\title{
Revenue-Sharing Contract Models for Logistics Service Supply Chains with Mass Customization Service
}

\author{
Weihua Liu, Xuan Zhao, and Runze Wu \\ College of Management and Economics, Tianjin University, Tianjin 300072, China \\ Correspondence should be addressed to Weihua Liu; lwhliu888@163.com
}

Received 13 April 2015; Revised 14 August 2015; Accepted 24 August 2015

Academic Editor: Young Hae Lee

Copyright (C) 2015 Weihua Liu et al. This is an open access article distributed under the Creative Commons Attribution License, which permits unrestricted use, distribution, and reproduction in any medium, provided the original work is properly cited.

\begin{abstract}
The revenue-sharing contract is one of the most important supply chain coordination contracts; it has been applied in various supply chains. However, studies related to service supply chains with mass customization (MC) are lacking. Considering the equity of benefit distribution between the members of service supply chains, in this paper, we designed two revenue-sharing contracts. The first contract for the maximum equity of a single logistics service integrator (LSI) and single functional logistics service provider (FLSP) in a two-echelon logistics service supply chain was designed by introducing the fair entropy function ("one to one" model). Furthermore, the method is extended to a more complex supply chain, which consists of a single LSI and multiple FLSPs. A new contract was designed not only for considering the equity of an LSI and each FLSP but also for the equity between each FLSP ("one to $N$ " model). The "one to one" model in three-echelon LSSC is also provided. The result exemplifies that, whether in the "one to one" model or "one to $N$ " model, there exists a best interval of customized level when the revenue-sharing coefficient reaches its maximum.
\end{abstract}

\section{Introduction}

The revenue-sharing coefficient is the key to designing a revenue-sharing contract, which is a form of supply chain coordination. The problem of designing a revenue-sharing mechanism for the product supply chain has been researched by many scholars for a long time $[1,2]$. With the rise of the logistics service industry, studies on revenue-sharing mechanisms of service supply chain have appeared in recent years [3]. But whether a revenue-sharing contract can be applied to a service supply chain has not been reported under MC background. Taking a logistics service supply chain, for example, through the integration of service capacity of upstream FLSPs, the LSI establishes the logistics service supply chain to provide customers with mass customization logistic service (MCLS) $[4,5]$. In MC, the customized level that was asked for by customers will affect the flexibility of service directly. But there is no exploration about whether the customized level will affect the application of the logistics service supply chain revenue-sharing contract.

In this paper, the motivation of research comes from practice and theory. From the practical level, as a new method to attract customers, mass customized service has obtained wide attention in recent years. Because of the capacity of providing scale service for multiple customers and providing customized service for individuals, mass customized service has dual characteristics of a scale effect and a customized effect. It has been applied in many industries such as insurance services [6], logistics services [7], and air services [8]. Under the environment of MCLS, in order to meet the customized demand of clients, downstream LSIs and upstream FLSPs have to address the coordination and profit distribution issue. Considering the customized level and the equity of profits, it is necessary to design a reasonable revenue-sharing contract to guarantee the stability of a logistics service supply chain. On the other hand, most of the existing revenue-sharing contract research mainly focuses on the coordination of a common product or service supply chain [3,9-11], but special cases such as the supply chain revenue-sharing contract research under the MCLS environment have not been reported before. The most closely related research to this paper is the one by Liu et al. [3]; they studied the method of determining the optimal revenue-sharing coefficient of twoechelon and three-echelon logistics service supply chains, but 
the study did not involve MCLS. In fact, MCLS and common services have two significant discrepancies; the first is that the customized level will affect the design of supply chain contracts. It is urgent to introduce the customized level into revenue-sharing contract design from the perspective of theory. The second is that MCLS is provided by an LSI via integrating FLSPs' service capacity; therefore, FLSPs have to evaluate the equity of profit distribution. So a way to introduce a fairness factor into a revenue-sharing contract is also necessary to be considered.

This paper expands the research content on the basis of Liu et al. [3]. First, this paper will take the MCLS environment into consideration and introduce the customized level as an important factor for the design of a revenue-sharing contract mechanism. Second, this paper is based on the logistics service supply chain of two echelons and establishes a revenue-sharing mechanism model in two relations by expanding the "one to one" relationship between the LSI and FLSP to "one to N." Finally, this paper aims at the maximum of fair entropy and setting improved fair entropy as the objective function of the model and then explores the influence of customized level on supply chain fair entropy, and some interesting findings are obtained. For example, whether in the case of "one to one" or "one to $N$," revenuesharing coefficients of the LSI will first increase and then decrease with the increase of the customized level; that is, there is an optimal interval of customized level that let the revenue-sharing coefficient of the LSI reach its maximum.

This paper is organized as follows: the second chapter is a literature review, in which we systematically review and summarize the studies of MC mode, service supply chain, and revenue-sharing contract. The third and fourth chapters introduce the procedure of model establishing. We will, respectively, illuminate the procedure of building "one to one" and "one to $N$ " service supply chain revenue-sharing contract models under the MC environment. The fifth chapter will conduct an example analysis. LINGO 11.0 will be used for the numerical simulation of the two models established in this paper. In last chapter, the conclusion, some important conclusions in this paper and management insights are summarized, and finally the limitation of this paper and future research directions are put forward.

\section{Literature Review}

Our research mainly concerns the order allocation decision under the situation of order insertion in the MCLS environment. Thus, the literature review is mainly related to the MC mode, order allocation, and order insertion. Our research direction will be proposed after summarizing the progression of developments in the literature as well as its current gaps.

2.1. MC Mode and Customized Level. In 1993, Pine II and Stan proposed that MC is a manufacturing mode to widely provide personalized products and services, which would be the frontier of commercial competition [12]. With 20 years' development and application, MC mode has become the main operation mode and the key to improving commercial competition. Including the autoindustry, clothing industry, and computer industry, many major economic industries benefit from this production mode [13]. Overall, most studies of MC mainly discuss the production modes, including the MC approach and its product design $[14,15]$, MC production planning and control technology $[16,17], \mathrm{MC}$ cost of production [18], and factors and conditions that affect MC [19]. With the increase of research on MC, many scholars review the literature in the field. Fogliatto made a detailed arrangement and summary of the literature from the 1980s. He indicated many unsolved problems with MC, like supply chain coordination and quality control issues, which would be the new fields of MC research [20].

The customized level is a crucial factor in MC. A high level of customization leads to a huge cost of production [21]. Enterprises will not produce the customized products to meet customers demand when the customized level is too high [22]. Therefore, it is important to define a rational customized level. Through a mathematical optimization model, some scholars have made specialized exploration. From the perspective of customer satisfaction and corporate customized cost, Liang and Zhou worked out the way to determine the optimal degree under the condition of fixed customized products supply capacity [23]. By building a mathematical model on the relationship between customized level, market demand, and corporate profits, Zhou et al. provided guidance for manufacturers to determine a rational customized level [24].

With more attention paid to service supply chains, some scholars began to research the customized level in MC service. Liu researched the method of determining an optimal customized level in a logistics service supply chain. They proposed three different decision-making modes for a customized level (the LSI decides the customized level; the customer decides the customized level, customized level decision of centralized supply chain), and these models discussed the reaction of profits of the LSI, customers, and the whole supply chain under different decision-making modes with the change of customized level, respectively [7]. Overall, most of MC research on customized levels is focused on product supply chain currently, but there is little research on service supply chains.

2.2. Logistics Service Supply Chain. With the development of the logistics industry, the logistics service supply chain has become the new hotspot in the supply chain field. Currently, research on logistics service supply chains mainly focuses on logistics service supply chain connotation [4, 25], logistics service supply chain coordinate mechanism $[3,26]$, empirical study of logistics service supply chain $[27,28]$, and selection and performance evaluation of FLSPs [5].

In the 21st century, with the rise in MC logistics service mode, research results show that logistics service supply chains under the background of MC are fruitful because of the endeavors of many scholars. For example, Rhonda et al. built an MC supply chain service model to meet the customers' demand of personality [29]. Liu et al. carried out research on the time scheduling problem under the mode of $\mathrm{MC}$ logistics service and constructed the time scheduling 
model of logistics service supply chain [30]. Subsequently, Liu et al. explored the order allocation problem of logistics service supply chains under MC background [3]. In addition, the decision-making problem of the customer order decoupling point (CODP) under MC service was also studied [31].

2.3. Revenue-Sharing Contract and Its Coefficient. A supply chain contract is an important means to promote the coordination of supply chain members. As a main form of supply chain contract, the revenue-sharing contract has become the hot topic in the supply chain coordination field because of its characteristics of effectively constraining supply chain members' behavior. The revenue-sharing contract plays a significant role in supply chain management, especially when confronting the uncertainty of customer demand [32]. Therefore, most research about revenue-sharing contracts assumes customer demand uncertainty and is mainly for two-echelon supply chains [33-36]. In recent years, revenue-sharing contract researches extended to more complex situations, more research concerning multiechelon supply chains and more constraints. Xiang proposed a revenue-sharing contract model with an assumption that supply chain members should share the cost as well as the revenue, which guarantees the rationality and fairness of the contract [37]. Considering the limitation of the two-echelon supply chain, van der Rhee et al. designed a revenue-sharing contract model for extended supply chain under stochastic demand (the extended supply chain is the multiechelon global supply chain that fits reality) [38].

As the key element when designing supply chain revenuesharing contracts, the revenue-sharing coefficient has been a concern for many years. For example, Giannoccaro established a revenue-sharing contract model in view of a threeechelon supply chain and presented a revenue-sharing coefficient range that can escalate the profits of supply chain members [39]. Pang designed a supply chain revenue-sharing model for stochastic demand. According to the model's result, with the increase of retailer's waste-averse decision bias, the coefficient of profit distribution of the retailer to the supplier will be decreased [10]. Qin found that if the revenue-sharing contract defines a coefficient inconsistent with reality, it will not be sustained. But the literatures above mainly focus on product supply chains; besides, they only gave the revenuesharing coefficient range instead of an accurate value [34]. Liu et al. put forward a method to confirm an optimal sharing coefficient of a two-echelon logistics service supply chain under stochastic-customer demand [3]. They also extended it to a three-echelon logistics service supply chain containing an LSI, an FLSP, and a logistics service subcontractor. But the research only contains a single LSI and single FLSP. It does not consider the MC environment and fairness factor when there are multiple FLSPs.

2.4. Summary of Literature Review. By combining the literature of three areas, we can find that the research on supply chain revenue-sharing contracts under the MC service environment is deficient. Moreover, equity between multiple FLSPs has not been considered in existing supply chain revenue-sharing contract research. Due to the shortage of

\begin{tabular}{|c|c|c|c|c|}
\hline \multirow{2}{*}{$\begin{array}{c}\text { Functional logistics } \\
\text { service provider } \\
S\end{array}$} & & \multirow{2}{*}{\begin{tabular}{|c|} 
Logistics \\
service \\
integrator $R$
\end{tabular}} & \multirow{2}{*}{$\frac{(D, t)}{P}$} & \multirow{2}{*}{$\begin{array}{c}\text { Customer } \\
(\text { manufacturing } \\
\text { retailer })\end{array}$} \\
\hline & $Q$ & & & \\
\hline
\end{tabular}

FIGURE 1: The two-echelon logistics service supply chain of a single LSI and single FLSP.

previous research, this paper will focus on the revenuesharing distribution mechanism problem of logistics service supply chains and then will consider an equity factor under MC mode. From the perspective of maximizing the equity perceived by supply chain members, this paper will set up two revenue-sharing contract models and investigate the influence of the customized level on supply chain revenuesharing coefficient and fair entropy.

\section{The "One to One" Model}

This paper focuses on the revenue-sharing contract mechanism design of two stages of logistics service supply chain with consideration of customer customization demand on the background of MC service. This chapter will exhibit the revenue-sharing contract model of logistics service supply chains considering customization demand. In Section 3.1, we will describe the problem and list basic assumptions of this model. In Section 3.2, the revenue-sharing contract model of two-echelon logistics service supply chains under consideration of a single LSI and a single FLSP is presented.

3.1. Problem Description. It is assumed that a two-echelon logistics service supply chain is composed of a single LSI $R$ and single FLSP $S$ which we called the "one to one" model. Figure 1 shows the procedure.

Figure 1 shows that the LSI will buy logistics service capacity from the FLSP to satisfy the customized demand when customers' orders contain a certain level of customization to LSI.

The notation of parameters and variables in this model is defined as follows.

Notations for the "One to One" Model

Decision Variables

Q: logistics capacity that $R$ needs to buy from $S$;

$t$ : customized level of logistics capacity that customer needs;

$\varphi$ : R's share of the total sales revenue under revenuesharing contract;

$1-\varphi$ : $S$ 's share of the total sales revenue under revenue-sharing contract.

\section{Other Parameters}

$C_{R}$ : marginal cost of LSI $R$;

$C_{u}(P)$ : the unit price of $R$ paying to customer when logistics service capability is lacking; 
$D(t)$ : the total demand of customer to logistics service under MC;

$H$ : the fair entropy, measuring revenue-sharing fairness of $R$ and $S$;

$H_{0}$ : threshold of fair entropy;

$P$ : unit price of service customer buys from $R$;

$S(Q)$ : expectation of the logistics capacity of $R$;

$U$ : the unit price when $R$ returns extra logistics capacity to $S$;

$w$ : the unit price when $R$ purchased services from $S$;

$\pi_{R}$ : total revenue of logistics service $R$, with $\pi_{R}^{\prime}$ indicating the total revenue of $R$ under revenue-sharing contract and $\pi_{R}^{\prime \prime}$ indicating the total revenue of $R$ under game situation;

$\pi_{S}$ : total revenue of $S$, with $\pi_{S}^{\prime}$ indicating the total revenue under revenue-sharing contract of $S$ and $\pi_{S}^{\prime \prime}$ indicating the total revenue under game situation of $S$;

$\pi_{T}$ : total revenue of whole logistics service supply chain, with $\pi_{T}^{\prime}$ indicating the total revenue of supply chain under revenue-sharing contract and $\pi_{T}^{\prime \prime}$ indicating the total revenue of supply chain under game situation;

$\mu$ : the average value of total customer service demand D;

$\sigma^{2}$ : the variance of total customer service demand $D$;

$\gamma$ : the weight of $R$ in supply chain relationship;

$1-\gamma$ : the weight of $S$ in supply chain relationship. lows.

Other assumptions of the "one to one" model are as fol-

Assumption 1. In order to explore the effect of different customer's customized level on a revenue-sharing contract, as in Liu et al.s study [7], assuming that customized level is a variable $t(t>0), t$ follows a kind of distribution which is not sure, and its distribution function is $F(t)$ and probability density function is $f(t)$. Since the customized level $t$ is a random variable, and it will change with different customers, so, referring to Liu et al. [7], we assume that $t$ is subject to a certain distribution.

Assumption 2. It is supposed that there is a correlation between customer demand and customized level [7, 24], which is assumed as $D(t)=D_{0}+k t-(1 / 2) h t^{2}$. We assume the average value of $D(t)$ is $\mu$ and variance is $\sigma^{2}$. This assumption is proposed to make it clear that the customer demand is related to the customized level. In practice, higher customized level may not lead to the increase of the customer demand, because too high customized level will increase the service price and finally will reduce the customer satisfaction. Referring to $[7,24]$, the demand function is set as $D(t)=$ $D_{0}+k t-(1 / 2) h t^{2}$.
Assumption 3. It is assumed that the LSI's marginal cost and the unit price when the LSI purchase service from FLSP are related to customized level, similar to Liu et al. [7]. It can be assumed that $C_{R}=C_{0}+z t$ and $w=w_{0}+y t$. Since the customized level will affect the cost of LSI, the higher the customized level is the higher the cost of LSI will be, so, referring to Liu et al. [7], the customized level will affect the wholesale price and the marginal cost of LSI.

Assumption 4. When the LSI purchases extra logistics service capacity, it is permitted to return the extra capacity to the FLSP and refund a unit price $U$ for the extra service capacity later. $U$ is related to the price $w$ for which the LSI purchases logistics capacity from the FLSP and variance $\sigma^{2}$ of demand. It is assumed that $U=w^{2} / l \sigma^{2}[3] ; l$ indicates the sensitivity coefficient of FLSP to demand variance. This assumption is proposed to guarantee that extra logistics service capacity will not be wasted and it should return to the FLSP in a proper way; the return price is referring to Liu et al. [3].

Assumption 5. In order to simplify the model, it is assumed that the FLSP has sufficient supply capacity of logistics service; namely, the FLSP does not lack any capacity when the LSI purchases service capacity from it.

Assumption 6. Under the revenue-sharing contract, the LSI and FLSP are in compliance with the principles of revenuesharing and loss sharing. It is assumed that the LSI and FLSP follow the ratio of $\varphi$ and $1-\varphi$ to distribute the total revenue of supply chain $[3,40]$. When the logistics service capacity purchased by the LSI from FLSP is not able to satisfy the customer demand, the LSI and FLSP should undertake compensation to the customer at a ratio of $\varphi$ and $1-\varphi$. In revenue-sharing contract, all the members should obey the rule of "revenue and loss sharing together;" this assumption is proposed to restrain the behavior of all the members.

3.2. The "One to One" Revenue-Sharing Contract Model. Referring to $[3,41]$, in the case of "one to one," the expectation of logistics service capacity purchased by the LSI is

$$
\begin{aligned}
S(Q) & =E(\min (Q, D(t))) \\
& =\int_{0}^{\infty} \min (Q, D(t)) f(t) d t \\
& =Q-\int_{0}^{Q}[Q-D(t)] f(t) d t \\
& =Q-\int_{0}^{Q}\left[Q-D_{0}-k t+\frac{1}{2} h t^{2}\right] f(t) d t .
\end{aligned}
$$

The expectation of the LSI's excess capacity is

$$
\begin{aligned}
E(Q-D(t))^{+} & =Q-S(Q) \\
& =\int_{0}^{Q}\left[Q-D_{0}-k t+\frac{1}{2} h t^{2}\right] f(t) d t .
\end{aligned}
$$


The capacity deficit expectation of the LSI is

$$
\begin{aligned}
E(D(t)-Q)^{+}= & \mu-S(Q) \\
= & \mu-Q \\
& +\int_{0}^{Q}\left[Q-D_{0}-k t+\frac{1}{2} h t^{2}\right] f(t) d t .
\end{aligned}
$$
is

The LSI revenue function under revenue-sharing contract

$$
\begin{aligned}
\pi_{R}= & \varphi P S(Q)-w Q-C_{R} Q-\varphi C_{u}(P)[\mu-S(Q)] \\
& -U[Q-S(Q)] .
\end{aligned}
$$

The revenue function of the FLSP is

$$
\begin{aligned}
\pi_{S}= & (1-\varphi) P S(Q)+w Q-C_{S} Q \\
& -(1-\varphi) C_{u}(P)[\mu-S(Q)]+U[Q-S(Q)] .
\end{aligned}
$$

The revenue of the whole supply chain is

$$
\begin{aligned}
\pi_{T} & =\pi_{R}+\pi_{S} \\
& =P S(Q)-C_{R} Q-C_{S} Q-C_{u}(P)[\mu-S(Q)] .
\end{aligned}
$$

In logistics service supply chains, usually the LSI is the leader and the FLSP is the follower [3]. In general, the LSI and FLSP coexist in two kinds of relationship; one is a game relationship; namely, the LSI and FLSP proceed with the Stackelberg game to maximize their own profits; the other is the revenue-sharing contract which will be studied in this paper. Under the revenue-sharing contract, supposing that there exists win-win cooperation between the LSI and FLSP, the two units can be treated as a whole, which generate a centralized decision-making model. Then maximizing the revenue of the whole supply chain is the final target. The condition of adopting the revenue-sharing contract is the fact that the profits gained by the LSI and FLSP under the revenue-sharing contract should be no less than the profits in Stackelberg game.

3.2.1. Model under Centralized Decision-Making. Under centralized decision-making, for obtaining the maximum revenue of a supply chain, the first-order condition should be satisfied:

$$
\frac{\partial E\left(\pi_{T}\right)}{\partial Q}=0
$$

Then the second derivative should be less than 0 ; that is, $\partial^{2} E\left(\pi_{T}\right) / \partial Q^{2}<0$.

Simplify the first-order condition:

$$
\begin{aligned}
& F(Q)+\left[\frac{1}{2} h Q^{2}+(1-k) Q-D_{0}\right] f(Q) \\
& =\frac{P-C_{R}-C_{S}+C_{u}(P)}{P+C_{u}(P)}=1-\frac{C_{R}+C_{S}}{P+C_{u}(P)} .
\end{aligned}
$$

We can calculate the optimal value of purchasing capacity $Q^{\prime}$ and optimal expectation of supply chain total revenue $E\left(\pi_{T}^{\prime}\right)$.
3.2.2. Model under Decentralized Decision-Making. For ensuring the implementation of the revenue-sharing contract, we need to investigate the Stackelberg game model between the LSI and FLSP, namely, a decentralized decision-making model.

For better understanding, we define that $b=\int_{0}^{Q}\left[Q-D_{0}-\right.$ $\left.k t+(1 / 2) h t^{2}\right] f(t) d t$; thus $S(Q)=Q-b$.

Another definition is $s=\partial b / \partial Q$; thus $s=F(Q)+$ $\left[(1 / 2) h Q^{2}+(1-k) Q-D_{0}\right] f(Q)$, and $\partial S(Q) / \partial Q=1-s$.

Respective expectation revenue of the LSI and FLSP is

$$
\begin{aligned}
E\left(\pi_{R}^{\prime \prime}\right)= & P(Q-b)-w Q-C_{R} Q-C_{u}(P)(\mu-Q+b) \\
& -\frac{w^{2}}{l \sigma^{2}} b
\end{aligned}
$$

$$
E\left(\pi_{S}^{\prime \prime}\right)=\left[w-C_{S}\right] Q+\frac{w^{2}}{l \sigma^{2}} b
$$

First, to maximize the profits of FLSP $S$, the first-order condition should be satisfied:

$$
\frac{\partial E\left(\pi_{S}^{\prime \prime}\right)}{\partial w}=Q+\frac{2 w}{l \sigma^{2}} b=0 .
$$

Then $w=-Q l \sigma^{2} / 2 b$.

Next, to maximize the profits of the LSI, the first-order condition should be satisfied:

$$
\frac{\partial E\left(\pi_{R}^{\prime \prime}\right)}{\partial Q}=\left[P+C_{u}(P)\right](1-s)-C_{R}-w-\frac{s w^{2}}{l \sigma^{2}}=0,
$$

while satisfying the fact that second derivative is less than 0 ; that is, $\partial^{2} E\left(\pi_{R}^{\prime \prime}\right) / \partial Q^{2}<0$.

We can obtain the optimal value of purchasing the capacity $Q^{\prime \prime}$ under the Stackelberg game. And by substituting $Q^{\prime \prime}$ into the expression of $w$, the corresponding $w$ can be calculated.

Under the constraints of rationality, the LSI and FLSP first consider their own profits. Only if their own profits are satisfied will the maximization of whole supply chain's revenue be considered. So the condition of supply chain members to accept the revenue-sharing contract is that the revenue obtained in this contract should be no less than that in the decentralized decision-making model. Thus the restraint is as follows:

$$
\begin{aligned}
& \varphi E\left(\pi_{T}^{\prime}\right) \geq E\left(\pi_{R}^{\prime \prime}\right) \\
&(1-\varphi) E\left(\pi_{T}^{\prime}\right) \geq E\left(\pi_{S}^{\prime \prime}\right) \\
& \Downarrow \\
& \frac{E\left(\pi_{R}^{\prime \prime}\right)}{E\left(\pi_{T}^{\prime}\right)} \leq \varphi \leq 1-\frac{E\left(\pi_{S}^{\prime \prime}\right)}{E\left(\pi_{T}^{\prime}\right)} .
\end{aligned}
$$

Formula (12) indicates that the constraints of the revenuesharing contract are transformed into constraints for the revenue-sharing coefficient. Namely, the revenue-sharing contract can be applied only when the revenue-sharing coefficient is in the interval mentioned above. 


\subsubsection{The Objective Function and Constraints of Optimal Revenue-Sharing Coefficient}

(1) Establishment of Objective Function. After satisfying the condition of revenue-sharing contract implementation, an optimal revenue-sharing coefficient should be confirmed to achieve fair distribution of profits between the LSI and FLSP, thereby maintaining the revenue-sharing relationship between them. The core idea to establish the objective function of supply chain optimal revenue-sharing coefficient is that the profit growth with unit-weight resource of each supply chain member is equal $[3,42]$. When the revenuesharing coefficient of the LSI is $\varphi$, the respective profit growth of the LSI and FLSP is

$$
\begin{aligned}
& \Delta \theta_{R}= \frac{E\left(\pi_{R}^{\prime}\right)-E\left(\pi_{R}^{\prime \prime}\right)}{E\left(\pi_{R}^{\prime \prime}\right)}, \\
& \Delta \theta_{S}=\frac{E\left(\pi_{S}^{\prime}\right)-E\left(\pi_{S}^{\prime \prime}\right)}{E\left(\pi_{S}^{\prime \prime}\right)} .
\end{aligned}
$$

Considering the different weights of the LSI and FLSP in the supply chain, suppose the weights of each are given. It is assumed that the weight of the LSI is $\gamma$; thus the weight of FLSP is $1-\gamma$; then the profit growth on unit-weight resource of the LSI and FLSP is

$$
\begin{aligned}
& \xi_{1}=\frac{\Delta \theta_{R}}{\varphi \gamma T_{R}}, \\
& \xi_{2}=\frac{\Delta \theta_{S}}{(1-\varphi)(1-\gamma) T_{S}} .
\end{aligned}
$$

The total cost of the LSI is

$$
\begin{aligned}
T_{R}= & w Q+C_{R} Q+\varphi C_{u}(P)[\mu-S(Q)] \\
& +V[Q-S(Q)] .
\end{aligned}
$$

The total cost of the FLSP is

$$
T_{S}=C_{S} Q+(1-\varphi) C_{u}(P)[\mu-S(Q)] .
$$

Then we introduce the concept of entropy, making the following standardized transformation to $\varepsilon_{1}$ and $\varepsilon_{2}$ [43]:

$$
\begin{aligned}
& \xi_{1}^{\prime}=\frac{\left(\xi_{1}-\bar{\xi}\right)}{\sigma}, \\
& \xi_{2}^{\prime}=\frac{\left(\xi_{2}-\bar{\xi}\right)}{\sigma} .
\end{aligned}
$$

Among them,

$$
\begin{aligned}
\bar{\xi} & =\frac{1}{2} \sum_{i=1}^{2} \xi_{i}, \\
\sigma & =\sqrt{\frac{1}{2} \sum_{i=1}^{2}\left(\xi_{i}-\bar{\xi}\right)^{2}} .
\end{aligned}
$$
$\varepsilon_{i}^{\prime}$

They are the average value and the standard deviation of
In order to eliminate the negative situation of $\xi_{1}^{\prime}$ and $\xi_{2}^{\prime}$, coordinate translation can be applied [44]. After translational transformation, $\xi_{i}^{\prime}$ turned into $\xi_{i}^{\prime \prime}: \xi_{i}^{\prime \prime}=K+\xi_{i}^{\prime} ; K$ is the range of coordinate translation. Then, calculating the ratio $\lambda_{i}$ of $\xi_{i}^{\prime \prime}$, set

$$
\begin{aligned}
& \lambda_{1}=\frac{\xi_{1}^{\prime \prime}}{\xi_{1}^{\prime \prime}+\xi_{2}^{\prime \prime}}, \\
& \lambda_{2}=\frac{\xi_{2}^{\prime \prime}}{\xi_{1}^{\prime \prime}+\xi_{2}^{\prime \prime}} .
\end{aligned}
$$

After obtaining $\lambda_{1}$ and $\lambda_{2}$, the fair entropy of whole supply chain is

$$
H=-\frac{1}{\ln m} \sum_{i=1}^{m} \lambda_{i} \ln \lambda_{i}
$$

The objective function of the optimal revenue-sharing coefficient in this model is as follows:

$$
H=-\frac{1}{\ln 2}\left(\lambda_{1} \ln \lambda_{1}+\lambda_{2} \ln \lambda_{2}\right) .
$$

(2) Constraint Condition. The constraint conditions of the model are as follows.

First, a certain constraint condition exists between the weight and revenue-sharing coefficient of the LSI and FLSP; it is shown as follows:

$$
\left|\frac{\varphi_{R}}{\varphi_{S}}-\frac{\gamma_{R}}{\gamma_{S}}\right| \leq \varepsilon .
$$

Namely, the absolute value of the difference between the specific value of the FLSP's weight and the specific value of revenue-sharing coefficient cannot exceed the critical value. The constraint condition mentioned above can be simplified as follows:

$$
\left|\frac{\varphi}{1-\varphi}-\frac{\gamma}{1-\gamma}\right| \leq \varepsilon .
$$

Second, threshold value $H_{0}$ can be set in reality; set $H \geq$ $H_{0}$. It indicates that the revenue distribution fairness of both sides of the supply chain should be greater than a certain threshold value.

Then the optimal revenue-sharing coefficient model under the condition of "one to one" is shown in the following formula:

$$
\begin{array}{ll}
\max & H=-\frac{1}{\ln 2}\left(\lambda_{1} \ln \lambda_{1}+\lambda_{2} \ln \lambda_{2}\right) \\
\text { s.t. } & \frac{E\left(\pi_{R}^{\prime \prime}\right)}{E\left(\pi_{T}^{\prime}\right)} \leq \varphi \leq 1-\frac{E\left(\pi_{S}^{\prime \prime}\right)}{E\left(\pi_{T}^{\prime}\right)} \\
& \left|\frac{\varphi}{1-\varphi}-\frac{\gamma}{1-\gamma}\right| \leq \varepsilon \\
& H \geq H_{0} .
\end{array}
$$




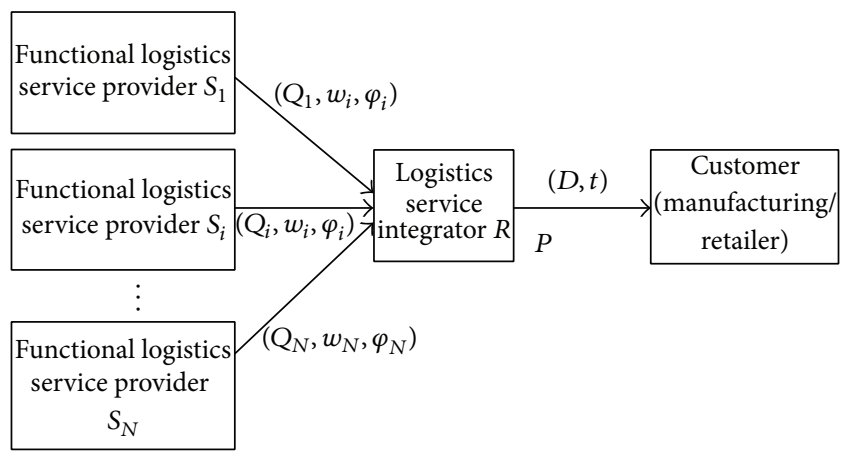

FIGURE 2: The two-echelon logistics service supply chain of "one to N."

This model is a single goal programming model. Under the condition of certain notations that are given, by making use of LINGO 11.0, we can program the objective function of the customized level and its constraint conditions and calculate the optimal customized level.

\section{The "One to $N$ " Model}

4.1. Problem Description. Another supply chain model researched in this paper is a two-echelon logistics service supply chain model which is composed of a single LSI and $N$ FLSPs (in a short form of one to $N$ ). The model operation schematic diagram is shown in Figure 2.

It is assumed that customers have $N$ kinds of demand. $N$ FLSPs are needed to satisfy the various demands. These demands have a certain similarity in that they belong to the same broad heading of logistics service. And MC is provided to customers by integrating these $N$ kinds of logistics service demand. As the number of optional FLSPs in reality is always greater than $N$, the LSI needs to choose $N$ from numerous FLSPs to meet the multiple customization demands and then provide service. The process of choosing FLSPs will not be considered in this paper, thus assuming that the N FLSPs have been chosen to accomplish the customization service. In this paper, research is focused on the revenue-sharing problem between the LSI and the decided $N$ FLSPs. The operation process of the "one to $N$ " model is as follows.

Firstly, the LSI will analyze the customization demand of logistics service asked by customers; then different FLSPs will be chosen by the LSI to purchase different logistics service capacity. Based on the given contract parameter $\left(w_{i}, \varphi_{i}\right)$, each FLSP will provide the optimal service capacity $Q_{i}$ to the LSI, and both sides realize their profits. In the case of "one to $N$," the LSI to each FLSP is same as "one to one," but, compared with the "one to one" model, three discrepancies should be considered in the "one to $N$ " model: first, the fairness between the LSI and each FLSP, second, the fairness factor of distribution between $N$ FLSP, and third, maximizing the total fair entropy of all FLSPs.

The same as in the "one to one" assumptions, the connotation of notations and variables in this model are as follows.
Notations for the "One to N" Model

Decision Variables

$Q_{i}$ : logistics capacity that $R$ needs to buy from $S_{i}$;

$t_{i}$ : customized level of $i$ logistics service capacity that customer needs;

$\varphi_{i}$ : the revenue-sharing coefficient of $R$ between the revenue-sharing contract of $R$ and $S_{i}$;

$1-\varphi_{i}$ : the revenue-sharing coefficient of $S_{i}$ between the revenue-sharing contract of $R$ and $S_{i}$.

\section{Other Parameters}

$C_{R i}$ : marginal cost of LSI $R$ aiming at the type $i$ of Customized service;

$C_{S i}$ : Production cost of unit logistics service of FLSPs aiming at the type $i$ of customized service;

$C_{u}\left(P_{i}\right)$ : the unit price of $R$ paying to customer when logistics service capability is lacking;

$D$ : the total demand of customer to logistics service under MC;

$D\left(t_{i}\right)$ : customization service demand faced by $S_{i}$;

$H_{1 i}$ : the fair entropy to measure the revenue-distribution fairness between $R$ and $S_{i}$ under revenuesharing contract;

$H_{2 i}$ : the fair entropy to measure the relative equity between $S_{i}$ and all of the other FLSPs;

$H$ : the total of all entropy;

$\mathrm{H}_{0}$ : threshold of fair entropy;

$i$ : FLSP $S_{i}, i=1,2, \ldots, N$;

$N$ : the number of all FLSPs;

$P_{i}$ : unit price of service customer purchasing type $i$ of customized service from $R$;

$S\left(Q_{i}\right)$ : expectation of the logistics capacity of $R$ aiming at type $i$ of customized service;

$S(Q)$ : expectation of the total logistics capacity of $R$, with $S(Q)=\sum_{i=1}^{N} S\left(Q_{i}\right)$;

$U_{i}$ : the unit price when $R$ returns extra logistics capacity to $S_{i}$;

$w_{i}$ : the unit price when $R$ purchased services from $S_{i}$ for type $i$ of customized service;

$\pi_{R i}$ : the profits of $R$ for customization service $i$, with $\pi_{R i}^{\prime}$ indicating the profits of $R$ under revenue-sharing contract and $\pi_{R i}^{\prime \prime}$ indicating the profits of $R$ under game situation;

$\pi_{R}$ : the total revenue of $R$, with $\pi_{R}=\sum_{i=1}^{N} \pi_{R i}$;

$\pi_{S i}$ : the total revenue of $S_{i}$, with $\pi_{S}^{\prime}$ indicating the total revenue of $S_{i}$ under revenue-sharing contract and $\pi_{S}^{\prime \prime}$ indicating the total revenue of $S_{i}$ under game situation; 
$\pi_{S}:$ the total revenue of all the FLSPs;

$\pi_{T i}$ : the total revenue of the supply chain composed of $S_{i}$ and $R$;

$\pi_{T}$ : the total revenue of the whole logistics service supply chain;

$\gamma_{i}$ : the weight of LSI in the supply chain composed of $R$ and $S_{I}$;

$1-\gamma_{i}$ : the weight of $S_{i}$ in the supply chain composed of $R$ and $S_{i}$.

Specific assumptions of the "one to $N$ " model are as follows; the practical basis of Assumptions 1, 2, and 4 is the same as "one to one" model.

Assumption 1. Assuming that the logistics capacity demands of customers exhibit diversity and assuming a customized level of each demand as $t_{i}$, the same as Liu et al. [7], set $t_{i}$ obeys a certain distribution, the distribution function is $F\left(t_{i}\right)$, and the probability density function is $f\left(t_{i}\right)$.

Assumption 2. It is assumed that there is a correlation between customer demand and customized level [7, 24]; setting the sum of customer customization demand faced by the LSI as $D$, the demand for each FLSP distributed by the LSI is $D\left(t_{i}\right)=D_{i 0}+k t_{i}-(1 / 2) t_{i}^{2}$. We assume the average value of $D\left(t_{i}\right)$ is $\mu_{i}$ and variance is $\sigma_{i}^{2}$.

Assumption 3. Similar to [5], the capacity supplied by each FLSP is independent; mutual utilization of different FLSP' capacities are forbidden forbidden. It will be a very complicated problem if their capacities are related mutually. So this assumption is proposed to guarantee the independence of each FLSP.

Assumption 4. Under a revenue-sharing contract, assume that the LSI and each FLSP follow the principle of revenuesharing and loss-sharing. According to the ratio of $\varphi_{i}$ and $1-\varphi_{i}$, the LSI and FLSP will, respectively, distribute the total revenue of the supply chain or undertake the loss of insufficient supply capacity.

Assumption 5. From the view of [45], assume that the revenue-sharing coefficients between the LSI and each FLSP are mutually visible in $N$ FLSPs.

The supply chain members perceive fairness by comparing the revenue-sharing coefficients in a proper way. If the coefficients are invisible, it will be difficult for each FLSP to assess relatively fairness.

4.2. Revenue-Sharing Model under Condition of "One to N". In the case of multiple FLSPs, each FLSP is still cooperating with the LSI one to one; then the capacity offered to customer is the total capacity purchased from all FLSPs. When the LSI cooperates with the FLSP $i$, the logistics capacity expectation of the LSI is

$$
\begin{aligned}
S\left(Q_{i}\right) & =E\left(\min \left(Q_{i}, D\left(t_{i}\right)\right)\right) \\
& =\int_{0}^{\infty} \min \left(Q_{i}, D\left(t_{i}\right)\right) f\left(t_{i}\right) d t \\
& =Q_{i}-\int_{0}^{Q_{i}}\left[Q_{i}-D\left(t_{i}\right)\right] f\left(t_{i}\right) d t \\
& =Q_{i}-\int_{0}^{Q_{i}}\left[Q_{i}-D_{0 i}-k t_{i}+\frac{1}{2} h t_{i}^{2}\right] f\left(t_{i}\right) d t .
\end{aligned}
$$

Expectation of the LSI's excess capacity is

$$
\begin{aligned}
E_{i} & \left(Q_{i}-D\left(t_{i}\right)\right)^{+}=Q_{i}-S\left(Q_{i}\right) \\
& =\int_{0}^{Q_{i}}\left[Q_{i}-D_{0 i}-k t_{i}+\frac{1}{2} h t_{i}^{2}\right] f\left(t_{i}\right) d t .
\end{aligned}
$$

Expectation of the LSI's insufficient capacity is

$$
\begin{aligned}
E_{i} & \left(D\left(t_{i}\right)-Q_{i}\right)^{+}=\mu_{i}-S\left(Q_{i}\right) \\
& =\mu_{i}-Q_{i}+\int_{0}^{Q_{i}}\left[Q_{i}-D_{0 i}-k t_{i}+\frac{1}{2} h t_{i}^{2}\right] f\left(t_{i}\right) d t .
\end{aligned}
$$

The revenue function of the LSI under a revenue-sharing contract is

$$
\begin{aligned}
\pi_{R i}= & \varphi_{i} P_{i} S\left(Q_{i}\right)-w_{i} Q_{i}-C_{R i} Q_{i} \\
& -\varphi_{i} C_{u}\left(P_{i}\right)\left[\mu_{i}-S\left(Q_{i}\right)\right]-U\left[Q_{i}-S\left(Q_{i}\right)\right] .
\end{aligned}
$$

The function of the LSI's total revenue is

$$
\begin{aligned}
\pi_{R i}= & \varphi_{i} P_{i} S\left(Q_{i}\right)-w_{i} Q_{i}-C_{R i} Q_{i} \\
& -\varphi_{i} C_{u}\left(P_{i}\right)\left[\mu_{i}-S\left(Q_{i}\right)\right]-U\left[Q_{i}-S\left(Q_{i}\right)\right]
\end{aligned}
$$

The revenue function of the FLSP $i$ is

$$
\begin{aligned}
\pi_{S i}= & \left(1-\varphi_{i}\right) P_{i} S\left(Q_{i}\right)+w_{i} Q_{i}-C_{S i} Q_{i} \\
& -\left(1-\varphi_{i}\right) C_{u}\left(P_{i}\right)\left[\mu_{i}-S\left(Q_{i}\right)\right] \\
& +U\left[Q_{i}-S\left(Q_{i}\right)\right] .
\end{aligned}
$$

The revenue function of a supply chain branch composed of the LSI and the FLSP $i$ is

$$
\begin{aligned}
\pi_{T i}= & \pi_{R i}+\pi_{S i} \\
= & P_{i} S\left(Q_{i}\right)-C_{R i} Q_{i}-C_{S i} Q_{i} \\
& -C_{u}\left(P_{i}\right)\left[\mu_{i}-S\left(Q_{i}\right)\right] .
\end{aligned}
$$

There is a relationship of a cooperative game existing between the LSI $R$ and each FLSP, and the process of the cooperative game is similar to that mentioned in the "one to one" model of third chapter. 
4.2.1. Centralized Decision-Making Model. Being similar to "one to one" situation, when the LSI obtains the optimal value of logistics capacity $Q_{i}$, it must be

$$
\frac{\partial E\left(\pi_{T i}\right)}{\partial Q_{i}}=0 .
$$

Satisfy the condition that second variance is less than 0 : $\partial^{2} E\left(\pi_{T i}\right) / \partial Q_{i}^{2}<0$.

Simplify the condition of first order:

$$
\begin{gathered}
F\left(Q_{i}^{\prime}\right)+\left[\frac{1}{2} h Q_{i}^{\prime 2}+(1-k) Q_{i}^{\prime}-D_{0}\right] f\left(Q_{i}^{\prime}\right) \\
=\frac{P_{i}-C_{R i}-C_{S i}+C_{u}\left(P_{i}\right)}{P_{i}+C_{u}\left(P_{i}\right)}=1-\frac{C_{R i}+C_{S i}}{P+C_{u}\left(P_{i}\right)} .
\end{gathered}
$$

From formula (33), we can calculate the optimal purchase volumes of logistics service $Q_{i}^{\prime}$ from the FLSP $i$ and the optimal expectation of profits $E\left(\pi_{T i}^{\prime}\right)$ of the $i$ supply chain branch.

The last formula is suitable for every supply chain branch, so the optimal purchase volumes of logistics capacity purchased from all FLSPs by the LSI can be calculated: $Q^{\prime}=$ $\sum_{i=1}^{N} Q_{i}^{\prime}$.

And the optimal expectation of supply chain total revenue is $E\left(\pi_{T}^{\prime}\right)=\sum_{i=1}^{N} E\left(\pi_{T i}^{\prime}\right)$.

4.2.2. Stackelberg Game Model. For the Stackelberg game, the revenue expectation functions of $R$ is

$$
\begin{aligned}
E\left(\pi_{R i}\right)= & P_{i}\left(Q_{i}-b_{i}\right)-w_{i} Q_{i}-C_{R} Q_{i} \\
& -C_{u}\left(P_{i}\right)\left(\mu_{i}-Q_{i}+b_{i}\right)-\frac{w_{i}^{2}}{k_{i} \sigma_{i}^{2}} b_{i} .
\end{aligned}
$$

The revenue expectation functions of $S_{i}$ is

$$
E\left(\pi_{S i}\right)=\left[w_{i}-C_{S i}\right] Q_{i}+\frac{w_{i}^{2}}{l_{i} \sigma_{i}^{2}} b_{i} .
$$

Before $R$ adopts the value of $Q_{i}$, the reaction of $w_{i}$ to $S_{i}$ should be considered. The calculation details of $w_{i}$ and $Q_{i}$ are shown in Appendix A.

For each supply chain branch, the condition of supply chain members who receive the revenue-sharing contract is that the revenue they obtain under this contract should not be less than that under decentralized decision-making. Consider

$$
\begin{array}{cc}
\varphi_{i} E\left(\pi_{T i}^{\prime}\right) \geq E\left(\pi_{R i}^{\prime \prime}\right) & \\
\left(1-\varphi_{i}\right) E\left(\pi_{T i}^{\prime}\right) \geq E\left(\pi_{S i}^{\prime \prime}\right) & i=1,2, \ldots, N \\
\Downarrow & \\
\frac{E\left(\pi_{R i}^{\prime \prime}\right)}{E\left(\pi_{T i}^{\prime}\right)} \leq \varphi_{i} \leq 1-\frac{E\left(\pi_{S i}^{\prime \prime}\right)}{E\left(\pi_{T i}^{\prime}\right)} & \\
&
\end{array}
$$

Under the "one to $N$ " condition, in order to apply the revenue-sharing contract, revenue-sharing coefficients between the LSI and each FLSP should satisfy the condition mentioned above.

\subsubsection{The Objective Function and Constraint Conditions of Optimal Revenue-Sharing Coefficient}

(1) Establishment of Objective Function. Under the case of multiple FLSPs, apart from the revenue-sharing fairness between the LSI and each FLSP, the fairness of the revenuesharing coefficient between multiple FLSPs should also be considered. So a new fair entropy is defined, which is composed of two parts, one is the fair entropy between the LSI and FLSP $i$, and the other is the fair entropy between the FLSP $i$ and other FLSPs.

(i) The Fair Entropy between the LSI and FLSP i. Similar to the establishment of fair entropy in the situation of "one to one," the core idea is that the profits' growth on unit-weight resource of each supply chain member is equal $[4,44]$. The calculation details of the fair entropy between the LSI and the FLSP $i$ are shown in Appendix B.

So, the fair entropy between the LSI and FLSP $i$ in this model is

$$
H_{1 i}=-\frac{1}{\ln 2}\left(\lambda_{R i} \ln \lambda_{R i}+\lambda_{S i} \ln \lambda_{S i}\right)
$$

(ii) The Fair Entropy between FLSP $i$ and Other FLSPs. As the revenue-sharing coefficient between the LSI and each FLSP is visible, each FLSP will perceive the fairness of the revenuesharing coefficient. So it is significant to take this part of fair entropy into consideration. The core idea of establishing the fair entropy is the relative equity of the revenue-sharing coefficient.

Assuming that the weight of each FLSP is $\omega_{i}$, and as the revenue-sharing coefficient of FLSP $i$ is $\left(1-\varphi_{i}\right)$, set $\eta_{i}=(1-$ $\left.\varphi_{i}\right) / \omega_{i}$.

Introducing the concept of entropy makes a transformation of $\eta_{i}: \eta_{i}^{\prime}=\left(\left(\eta_{i}-\bar{\eta}_{i}\right) / \sigma_{\eta}\right) \bar{\eta}_{i}$ is the average value of $\eta_{i} ; \sigma_{\eta}$ is the standard deviation of $\eta_{i}$. For eliminating the negative value, make a coordinate translation: $\eta_{i}^{\prime \prime}=\eta_{i}^{\prime}+$ $K_{2}, K_{2}$ is the range of coordinate translation. Then proceed with the normalization: $\rho_{i}=\eta_{i}^{\prime \prime} / \sum_{i=1}^{N} \eta_{i}^{\prime \prime}$. Finally, calculate the fair entropy value between the FLSP and others: $H_{2 i}=$ $-(1 / \ln N)\left(\sum_{i=1}^{N} \rho_{i} \ln \rho_{i}\right)$.

(iii) Objective Function of Total Fair Entropy. In the case of "one to $N$," maximizing the total fair entropy is the connotation of objective function in this model. For FLSP $i$, two parts are combined in fair entropy; they are the fair entropy between the LSI and FLSP $i$ and the fair entropy between FLSP $i$ and other FLSPs. So the summation of $N$ FLSPs' fair entropies is

$$
\begin{aligned}
H & =\sum_{i=1}^{N} H_{i}=-\sum_{i=1}^{N}\left[\frac{1}{\ln 2}\left(\lambda_{R i} \ln \lambda_{R i}+\lambda_{S i} \ln \lambda_{S i}\right)\right. \\
& \left.+\frac{1}{\ln N}\left(\sum_{i=1}^{N} \rho_{i} \ln \rho_{i}\right)\right] .
\end{aligned}
$$




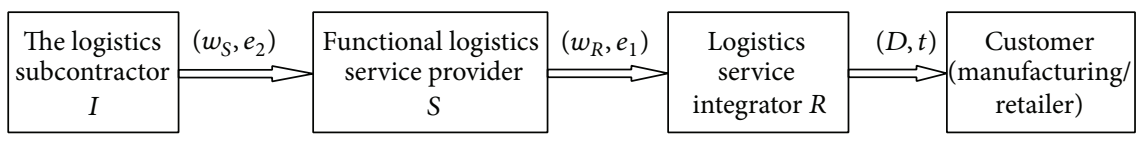

FIgURE 3: The model of three-echelon LSSC.

(2) Establishing the Constrains. To be similar to the "one to one" model, the "one to $N$ " model restrains the absolute value of the difference between the ratio of the revenue-sharing coefficient of the LSI and that of FLSP to be not greater than the critical value. For equity, we assume the threshold value of total fair entropy is $H_{0}$; set $H>H_{0}$. Under the condition of "one to $N$," the model of the optimal revenue-sharing coefficient is shown in the following formula:

$$
\begin{array}{ll}
\max & H=-\sum_{i=1}^{N}\left[\frac{1}{\ln 2}\left(\lambda_{R i} \ln \lambda_{R i}+\lambda_{S i} \ln \lambda_{S i}\right)+\frac{1}{\ln N}\left(\sum_{i=1}^{N} \rho_{i} \ln \rho_{i}\right)\right] \\
\text { s.t. } & \frac{E\left(\pi_{R i}^{\prime \prime}\right)}{E\left(\pi_{T i}^{\prime}\right)} \leq \varphi_{i} \leq 1-\frac{E\left(\pi_{S i}^{\prime \prime}\right)}{E\left(\pi_{T i}^{\prime}\right)} \\
& \left|\frac{\varphi_{i}}{1-\varphi_{i}}-\frac{\gamma_{i}}{1-\gamma_{i}}\right| \leq \varepsilon_{i} \\
& H \geq H_{0} .
\end{array}
$$

This model is a single objective programming model and is aimed at calculating $\varphi_{i}(i=1,2, \ldots, N)$. Under the condition of given notations, the model can be programmed using LINGO 11.0 to find the optimal customized level.

\section{Model Extension: The "One to One" Model of Three-Echelon Logistics Service Supply Chains}

Now we extend the "one to one" and "one to $N$ " models to three-echelon logistics service supply chains. Since the way to extend the two models is the same, the "one to one" model of three-echelon LSSC is chosen to be described in detail. In Section 5.1, we will describe the problem and list basic assumptions of this model. In Section 5.2, the revenuesharing contract model of three-echelon logistics service supply chains under consideration of a single LSI, a single FLSP, and a single subcontractor is presented.

5.1. Problem Description. In practice, the supply chain members always contain more than the LSP and the FLSP; it is assumed that the FLSP subcontracts its logistics capacity to the upstream logistics subcontractor $I$, so there are three participants in LSSC. The model of the three-echelon LSSC is shown in Figure 3. Notations for the "One to One" Model of Three-Echelon LSSC are given as follows.

Notations for the "One to One" Model of Three-Echelon LSSC

\section{Decision Variables}

$Q$ : logistics capacity that $R$ needs to buy from $S$; $t$ : customized level of logistics capacity that customer needs; $e_{1}: R$ 's share of the sales revenue under revenue-sharing contract of $R$ and $S$;

$1-e_{1}: S$ s share of the sales revenue under revenuesharing contract of $R$ and $S$;

$e_{2}: S$ 's share of the sales revenue under revenue-sharing contract of $S$ and $I$;

$1-e_{2}$ : I's share of the sales revenue under revenuesharing contract of $S$ and $I$.

\section{Other Parameters}

$C_{R}:$ marginal cost of LSI $R$;

$C_{u}(P)$ : the unit price of $R$ paying to customer when logistics service capability is lacking;

$D(t)$ : the total demand of customer to logistics service under $\mathrm{MC}$;

$H$ : the fair entropy, measuring revenue-sharing fairness of $R$ and $S$;

$H_{0}$ : threshold of fair entropy;

$P$ : unit price of service customer buys from $R$;

$S(Q)$ : expectation of the logistics capacity of $R$;

$U$ : the unit price when $R$ returns extra logistics capacity to $S$;

$w_{R}$ : The unit price when $R$ purchased services from $S$; $w_{S}$ : The unit price when $S$ purchased services from $I$;

$\pi_{R}$ : total revenue of logistics service $R$, with $\pi_{R 1}$ indicating the total revenue of $R$ under revenue-sharing contract and $\pi_{R 2}$ indicating the total revenue of $R$ under game situation; 
$\pi_{S}$ : total revenue of $S$, with $\pi_{S 1}$ indicating the total revenue under revenue-sharing contract of $S$ and $\pi_{S 2}$ indicating the total revenue under game situation of $S$;

$\pi_{I}$ : total revenue of $I$, with $\pi_{I 1}$ indicating the total revenue under revenue-sharing contract of $I$ and $\pi_{I 2}$ indicating the total revenue under game situation of $I$

$\pi_{T}$ : total revenue of whole logistics service supply chain, with $\pi_{T 1}$ indicating the total revenue of supply chain under revenue-sharing contract and $\pi_{T 2}$ indicating the total revenue of supply chain under game situation;

$\mu$ : the average value of total customer service demand $D$;

$U_{1}$ : unit price paid to $S$ when $R$ has extra capacity, with $U_{1}=w_{R}^{2} / l_{1} \sigma^{2}$

$U_{2}$ : unit price paid to $I$ when $S$ has extra capacity, with $U_{2}=w_{S}^{2} / l_{2} \sigma^{2}$

$\sigma^{2}$ : the variance of total customer service demand $D$;

$\gamma^{\prime}$ : the weight of $R$ in the relationship of $S$ and $R$;

$1-\gamma^{\prime}$ : the weight of $S$ in the relationship of $S$ and $R$;

$\gamma^{\prime \prime}$ : the weight of $S$ in the relationship of $S$ and $I$;

$1-\gamma^{\prime \prime}$ : the weight of $I$ in the relationship of $S$ and $I$.

5.2. The "One to One" Model in Three-Echelon LSSC. In the revenue-sharing contract of the "one to one" model in threeechelon LSSC, the revenue expectation functions of LSI, FLSP, subcontractor, and the entire LSSC are as follows.

The revenue of the integrator $R$ is

$$
\begin{aligned}
\pi_{R}= & e_{1} P S(Q)-w_{R} Q-C_{R} Q-e_{1} C_{u}(P)[\mu-S(Q)] \\
& -U_{1}[Q-S(Q)] .
\end{aligned}
$$

The revenue of the functional service provider $S$ is

$$
\begin{aligned}
\pi_{S}= & e_{2}\left[\left(1-e_{1}\right) P S(Q)+w_{R} Q\right]-C_{S} Q-w_{S} Q \\
& -e_{2}\left(1-\varphi_{2}\right) C_{u}(P)[\mu-S(Q)] \\
& +U_{1}[Q-S(Q)]-U_{2}[Q-S(Q)] .
\end{aligned}
$$

The revenue of the subcontractor $I$ is

$$
\begin{aligned}
\pi_{I}= & \left(1-e_{2}\right)\left[\left(1-e_{1}\right) P S(Q)+w_{R} Q\right]+w_{R} Q-C_{I} Q \\
& -\left(1-e_{2}\right)\left(1-e_{1}\right) C_{u}(P)[\mu-S(Q)] \\
& +U_{2}[Q-S(Q)] .
\end{aligned}
$$
is

Under centralized control, the revenue of the entire LSSC

$$
\begin{aligned}
\pi_{T}= & \pi_{R}+\pi_{S}+\pi_{I} \\
= & P S(Q)-C_{R} Q-C_{S} Q-C_{I} Q \\
& -C_{u}(P)[\mu-S(Q)] .
\end{aligned}
$$

5.2.1. Centralized Decision-Making Model. Being similar to "one to one" situation in two-echelon supply chain, when the LSI obtains the optimal value of logistics capacity, it must satisfy

$$
\frac{\partial E\left(\pi_{T}\right)}{\partial Q}=0
$$

Then the second derivative should be less than 0 ; that is, $\partial^{2} E\left(\pi_{T}\right) / \partial Q^{2}<0$.

Simplify the first-order condition:

$$
\begin{gathered}
F(Q)+\left[\frac{1}{2} h Q^{2}+(1-k) Q-D_{0}\right] f(Q) \\
=\frac{P-C_{R}-C_{S}-C_{I}+C_{u}(P)}{P+C_{u}(P)} \\
=1-\frac{C_{R}+C_{S}+C_{I}}{P+C_{u}(P)} .
\end{gathered}
$$

We can calculate the optimal value of purchasing capacity $Q_{1}$ and optimal expectation of supply chain total revenue $\pi_{T 1}$.

5.2.2. Stackelberg Game Model. For the Stackelberg game, the revenue expectation functions of $R$ are

$$
\begin{aligned}
E\left(\pi_{R 2}\right)= & P(Q-b)-w_{R} Q-C_{R} Q \\
& -C_{u}(P)(\mu-Q+b)-\frac{w_{R}^{2}}{l_{1} \sigma^{2}} b .
\end{aligned}
$$

The revenue expectation functions of $S$ are

$$
E\left(\pi_{S 2}\right)=\left[w_{R}-C_{S}-C_{I}\right] Q+\frac{w_{R}^{2}}{l_{1} \sigma^{2}} b-\frac{w_{S}^{2}}{l_{2} \sigma^{2}} b .
$$

The revenue expectation functions of $I$ are

$$
E\left(\pi_{I 2}\right)=\left[w_{S}-C_{I}\right] Q+\frac{w_{S}^{2}}{l_{2} \sigma^{2}} b
$$

Before $R$ adopts the value of $Q$, the reaction of $w_{R}$ to $S$ should be considered, while $S$ make decision on $I$. The calculation details are shown in Appendix C.

Under the constraints of rationality, the LSI, FLSP, and subcontractor will first consider their own profits. Only if their own profits are satisfied will the maximization of whole supply chain's revenue be considered. So the condition of supply chain members to accept the revenue-sharing contract is that the revenue obtained in this contract should be no less 
than that in the decentralized decision-making model. Thus the restraint is listed as follows:

$$
\begin{aligned}
& e_{1} E\left(\pi_{T}^{\prime}\right) \geq E\left(\pi_{R}^{\prime \prime}\right) \\
& \left(1-e_{1}\right) e_{2} E\left(\pi_{T}^{\prime}\right) \geq E\left(\pi_{S}^{\prime \prime}\right) \\
& \left(1-e_{1}\right)\left(1-e_{2}\right) E\left(\pi_{T}^{\prime}\right) \geq E\left(\pi_{I}^{\prime \prime}\right) \\
& \Downarrow \\
& \frac{E\left(\pi_{R}^{\prime \prime}\right)}{E\left(\pi_{T}^{\prime}\right)} \leq e_{1} \leq 1-\frac{E\left(\pi_{S}^{\prime \prime}\right)+E\left(\pi_{I}^{\prime \prime}\right)}{E\left(\pi_{T}^{\prime}\right)} \\
& \frac{E\left(\pi_{S}^{\prime \prime}\right)}{\left(1-e_{1}\right) E\left(\pi_{T}^{\prime}\right)} \leq e_{2} \leq 1-\frac{E\left(\pi_{I}^{\prime \prime}\right)}{\left(1-e_{1}\right) E\left(\pi_{T}^{\prime}\right)} .
\end{aligned}
$$

\subsubsection{The Objective Function and Constraint Conditions of Optimal Revenue-Sharing Coefficient}

(1) Objective Function. Similar to the establishment of fair entropy in the situation of "one to one," the core idea is that the profits' growth on unit-weight resource of each supply chain member is equal. The calculation details of the fair entropy between $R, S$, and $I$ are shown in Appendix D.

So, the fair entropy in this model is

$$
H=-\frac{1}{\ln 3}\left(\lambda_{1} \ln \lambda_{1}+\lambda_{2} \ln \lambda_{2}+\lambda_{3} \ln \lambda_{3}\right) .
$$

(2) Constraint Condition. The constraint conditions of the model are listed as follows.

First, a certain constraint condition exists between the weight and revenue-sharing coefficient of the LSI and the FLSP and the FLSP and the subcontractor; $\gamma^{\prime}$ represents the weight of LSI in the whole LSSC; $\gamma^{\prime \prime}$ represents the weight of FLSP in the relationship of FLSP and subcontractor; it is shown as follows:

$$
\begin{aligned}
& \left|\frac{e_{R}}{e_{S}}-\frac{\gamma_{R}}{\gamma_{S}}\right| \leq \varepsilon, \\
& \left|\frac{e_{S}}{e_{I}}-\frac{\gamma_{S}}{\gamma_{I}}\right| \leq \varepsilon .
\end{aligned}
$$

The constraint condition mentioned above can be simplified as follows:

$$
\begin{array}{r}
\left|\frac{e_{1}}{\left(1-e_{1}\right) e_{2}}-\frac{\gamma^{\prime}}{\left(1-\gamma^{\prime}\right) \gamma^{\prime \prime}}\right| \leq \varepsilon, \\
\left|\frac{\left(1-e_{1}\right) e_{2}}{\left(1-e_{1}\right)\left(1-e_{2}\right)}-\frac{\left(1-\gamma^{\prime}\right) \gamma^{\prime \prime}}{\left(1-\gamma^{\prime}\right)\left(1-\gamma^{\prime \prime}\right)}\right| \leq \varepsilon .
\end{array}
$$

Second, threshold value $H_{0}$ can be set in reality; set $H \geq$ $H_{0}$. It indicates that the revenue distribution fairness of each side of the supply chain should be greater than a certain threshold value.
Then the optimal revenue-sharing coefficient model under the condition of "one to one" is shown in the following formula:

$$
\begin{array}{ll}
\max & H=-\frac{1}{\ln 3}\left(\lambda_{1} \ln \lambda_{1}+\lambda_{2} \ln \lambda_{2}+\lambda_{3} \ln \lambda_{3}\right) \\
\text { s.t. } & \frac{E\left(\pi_{R}^{\prime \prime}\right)}{E\left(\pi_{T}^{\prime}\right)} \leq e_{1} \leq 1-\frac{E\left(\pi_{S}^{\prime \prime}\right)+E\left(\pi_{I}^{\prime \prime}\right)}{E\left(\pi_{T}^{\prime}\right)} \\
& \frac{E\left(\pi_{S}^{\prime \prime}\right)}{\left(1-e_{1}\right) E\left(\pi_{T}^{\prime}\right)} \leq e_{2} \leq 1-\frac{E\left(\pi_{I}^{\prime \prime}\right)}{\left(1-e_{1}\right) E\left(\pi_{T}^{\prime}\right)} \\
& \left|\frac{e_{1}}{\left(1-e_{1}\right) e_{2}}-\frac{\gamma^{\prime}}{\left(1-\gamma^{\prime}\right) \gamma^{\prime \prime}}\right| \leq \varepsilon \\
& \left|\frac{\left(1-e_{1}\right) e_{2}}{\left(1-e_{1}\right)\left(1-e_{2}\right)}-\frac{\left(1-\gamma^{\prime}\right) \gamma^{\prime \prime}}{\left(1-\gamma^{\prime}\right)\left(1-\gamma^{\prime \prime}\right)}\right| \leq \varepsilon \\
& H \geq H_{0} .
\end{array}
$$

This model is a single goal programming model. Under the condition of certain notations that are given, by making use of LINGO 11.0, we can program the objective function of the customized level and its constraints and calculate the optimal customized level.

\section{The Numerical Analysis}

This chapter will illustrate the validity of the model by specific example and explore the effect that the customized level has on the optimal revenue-sharing coefficient of the supply chain and fair entropy, finally giving a specific suggestion for applying the revenue-sharing contract. For all parameters used in numerical example, we have already made them dimensionless. The example analysis is conducted with a PC with $2.4 \mathrm{GHz}$ dual-core processor, 2 gigabytes of memory, and windows 7 system; we programmed and simulated numerical results using LINGO 11 software. The content of this chapter is arranged as follows. In Section 6.1, numerical analysis of "one to one" model is presented; in Section 6.2, numerical analysis of "one to $N$ " model is presented; in Section 6.3, the numerical analysis of the "one to one" model in three-echelon LSSC is provided. In Section 6.4, a discussion based on the results of Sections 6.1 to 6.3 is presented.

6.1. The Numerical Analysis of the "One to One" Model. The notations and formulas involved in the logistics service supply chain model composed of a single LSI and a single FLSP are as follows.

It is assumed that customized level $t$ follows the uniform distribution in interval of $[0,8]$; that is $t \sim U(0,8), D(t)=$ $6+1.8 t-0.5 t^{2}, C_{R}=0.6+0.25 t, w=0.4+0.5 t, P=15$, $C_{u}(P)=4, C_{S}=0.4, l=2, \mu=10, \sigma^{2}=8, \gamma=0.6$, and $H_{0}=0.6$. Most of the data used here are referring to Liu et al. [3]; others are assumed according to the practical business data.

By changing the value of the customized level, the variation trend of the corresponding revenue-sharing coefficient 


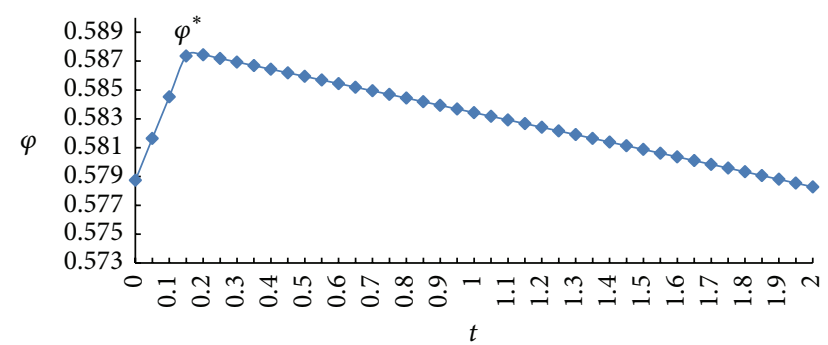

FIgURE 4: $\varphi$ value curve under a different customized level.

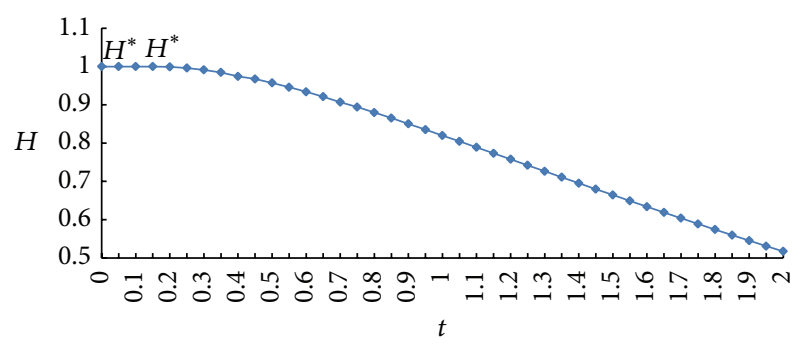

FIgURE 5: $H$ value curve under a different customized level.

and overall fair entropy can be worked out. The customized level $t$ obeys the uniform distribution in $[0,8]$. From the application result, when $t$ is greater than 2, then the fair entropy will be lower than 0.5 , as shown by Figure 4 , which indicates that the unfair level is high. So the case of $t>2$ will not be considered.

As shown by Figures 4 and 5, according to the results, the graphs of the optimal revenue-sharing coefficient $\varphi$ and fair entropy $H$ changing with customized level are presented.

As shown in Figure 4, with an increase in customized level, the optimal revenue-sharing coefficient first increased and then decreased, and the speed of increase is greater than the speed of decrease. The optimal revenue-sharing coefficient reaches its maximum at $H=0.2$ when $\varphi^{*}=0.5874$.

As shown by Figure 5, with the value of $t$ in the interval of $[0,0.15]$, the fair entropy can reach the maximum, that is $H^{*}=1$. When $t>1.5$, with the increase of the customized level, fair entropy decreases gradually with a low speed. When $t=2$ and $H=0.517$, the fair entropy reaches a very low level.

In this model, in order to discuss the influence of final service price on revenue and fair entropy, we choose $P=14.6$ and $P=15.4$ to compare with the initial price $P=15$, and the changes of revenue-sharing coefficients under different prices are shown in Figure 6; the changes of fair entropy under different prices are shown in Figure 7.

As shown in Figure 6, for a certain customized level, with an increase of the price, the optimal revenue-sharing coefficient is increased, which means the increase of price will benefit the integrator.

As shown in Figure 7, the fair entropy can reach the maximum under different prices; that is, $H^{*}=1$, and then the fair entropy decreases gradually with a low speed. It should be noticed that, with an increase of the price, the fair entropy will decrease under the certain customized level.

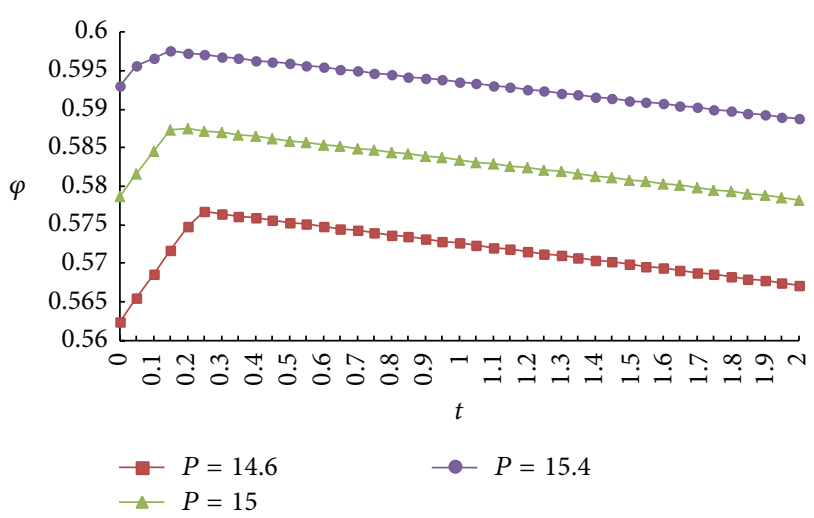

FIGURE 6: $\varphi$ value curve under different prices.

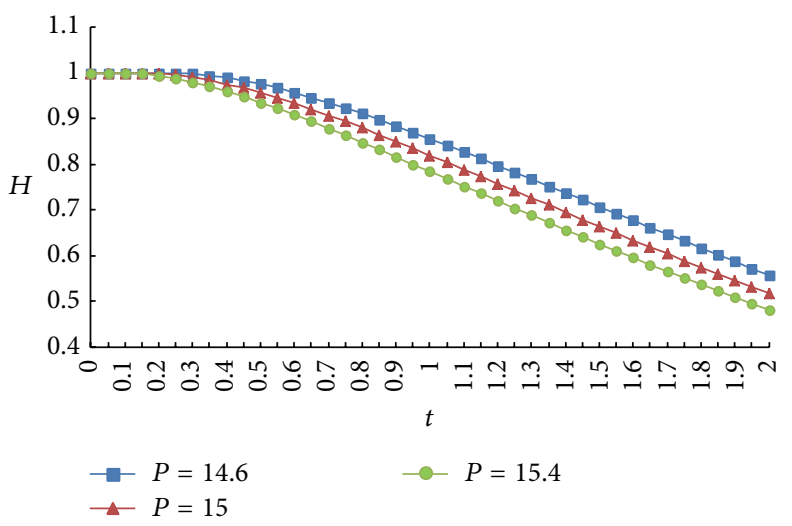

Figure 7: $H$ value curve under different prices.

6.2. The Numerical Analysis of the "One to N" Model. Facing the "one to $N$ " condition, this paper chose a typical example of a single LSI and three FLSPs to analyze. The notations of each FLSP are different and are given as follows.

FLSP 1: it is assumed that customized level $t_{1}$ follows uniform distribution on $[0,8.5]$; that is, $t_{1} \sim U(0,8), D\left(t_{1}\right)=$ $6+1.8 t_{1}-0.5 t_{1}{ }^{2}, C_{R 1}=0.6+1 / 3 * t_{1}, w_{1}=0.4+1 / 3 * t_{1}$, $P_{1}=15, C_{u}\left(P_{1}\right)=4, C_{S 1}=0.4, l_{1}=2, \mu_{1}=10, \sigma_{1}{ }^{2}=8$, and $\gamma_{1}=0.7$.

FLSP 2: it is assumed that customized level $t_{2}$ follows uniform distribution on $[0,8]$; that is, $t_{1} \sim U(0,8), D\left(t_{2}\right)=$ $6+1.9 t_{2}-0.5 t_{2}{ }^{2}, C_{R 2}=0.6+1 / 4 * t_{2}, w_{2}=0.4+1 / 3 * t_{2}$, $P_{2}=15, C_{u}\left(P_{2}\right)=3.8, C_{S 2}=0.4, l_{2}=2, \mu_{2}=10.1, \sigma_{2}{ }^{2}=8.1$, and $\gamma_{2}=0.65$.

FLSP 3: it is assumed that customized level $t_{3}$ follows uniform distribution on $[0,7.5]$; that is, $t_{3} \sim U(0,8), D\left(t_{3}\right)=$ $6+1.85 t_{3}-0.25 t_{3}{ }^{2}, C_{R 3}=0.55+1 / 3 * t_{3}, w_{3}=0.4+1 / 3 * t_{3}$, $P_{3}=15, C_{u}\left(P_{3}\right)=4.1, C_{S 3}=0.4, l_{3}=2, \mu_{3}=9.8, \sigma_{3}^{2}=8$, and $\gamma_{3}=0.65$.

Most of the data used here are referring to Liu et al. [3]; others are assumed according to the practical business situation.

As the arbitrary value of the uniform distribution interval can be chosen by the customized level of three FLSPs, for finding the effect of different customized level combinations on the optimal revenue-sharing coefficient, we assume that 
TABLE 1: Example analysis result of one to $N$ model.

\begin{tabular}{lccccccc}
\hline$M$ & $\varphi_{1}$ & $\varphi_{2}$ & $\varphi_{3}$ & $H_{11}$ & $H_{12}$ & $H_{13}$ & $H$ \\
\hline 0 & 0.5796 & 0.5886 & 0.5682 & 0.9999 & 0.9999 & 0.9999 & 0.9988 \\
0.2 & 0.5805 & 0.5903 & 0.5720 & 0.9999 & 0.9999 & 0.9999 & 0.9988 \\
0.4 & 0.5814 & 0.5919 & 0.5757 & 0.9999 & 0.9999 & 0.9999 & 0.9988 \\
0.6 & 0.5823 & 0.5935 & 0.5794 & 0.9999 & 0.9999 & 0.9999 & 0.9987 \\
0.8 & 0.5831 & 0.5951 & 0.5830 & 0.9999 & 0.9999 & 0.9999 & 0.9987 \\
1 & 0.5840 & 0.5967 & 0.5866 & 0.9999 & 0.9999 & 0.9999 & 0.9986 \\
1.2 & 0.5849 & 0.5983 & 0.5900 & 0.9999 & 0.9998 & 0.9999 & 0.9985 \\
1.4 & 0.5857 & 0.5990 & 0.5922 & 0.9999 & 0.9997 & 0.9997 & 0.9984 \\
1.6 & 0.5865 & 0.5989 & 0.5917 & 0.9999 & 0.9987 & 0.9972 & 0.9979 \\
1.8 & 0.5872 & 0.5987 & 0.5912 & 0.9999 & 0.9970 & 0.9923 & 0.9968 \\
2 & 0.5871 & 0.5985 & 0.5907 & 1.0000 & 0.9946 & 0.9854 & 0.9953 \\
2.2 & 0.5870 & 0.5983 & 0.5902 & 0.9999 & 0.9917 & 0.9766 & 0.9934 \\
2.4 & 0.5868 & 0.5981 & 0.5897 & 0.9995 & 0.9881 & 0.9663 & 0.9910 \\
2.6 & 0.5866 & 0.5979 & 0.5891 & 0.9985 & 0.9840 & 0.9546 & 0.9882 \\
2.8 & 0.5865 & 0.5978 & 0.5886 & 0.9977 & 0.9795 & 0.9417 & 0.9851 \\
3 & 0.5864 & 0.5976 & 0.5881 & 0.9966 & 0.9745 & 0.9276 & 0.9818 \\
3.2 & 0.5862 & 0.5974 & 0.5876 & 0.9953 & 0.9691 & 0.9127 & 0.9782 \\
3.4 & 0.5862 & 0.5972 & 0.5870 & 0.9946 & 0.9632 & 0.8970 & 0.9745 \\
3.6 & 0.5860 & 0.5970 & 0.5865 & 0.9931 & 0.9571 & 0.8806 & 0.9705 \\
3.8 & 0.5859 & 0.5968 & 0.5860 & 0.9914 & 0.9506 & 0.8635 & 0.9663 \\
4 & 0.5858 & 0.5966 & 0.5854 & 0.9895 & 0.9438 & 0.8460 & 0.9620 \\
4.2 & 0.5856 & 0.5965 & 0.5849 & 0.9875 & 0.9368 & 0.8281 & 0.9575 \\
4.4 & 0.5855 & 0.5963 & 0.5844 & 0.9853 & 0.9295 & 0.8098 & 0.9528 \\
4.6 & 0.5854 & 0.5961 & 0.5838 & 0.9830 & 0.9219 & 0.7912 & 0.9481 \\
4.8 & 0.5852 & 0.5959 & 0.5833 & 0.9806 & 0.9142 & 0.7724 & 0.9433 \\
5 & 0.5852 & 0.5957 & 0.5827 & 0.9793 & 0.9043 & 0.7533 & 0.9382 \\
\hline
\end{tabular}

the customized level of each demand of three FLSPs has an initial value of $t_{1}=0.1, t_{2}=0.2$, and $t_{3}=0.4$, respectively; then zoom in (or out) the three customized levels to a specific ratio $M$ at the same time and study the variation in the optimal revenue-sharing coefficient value under different $M$ with $M$ being the independent variable. The data result is shown in Table 1.

Based on the result shown in Table 1, trend charts of $M$ to three absolutely fair entropies (fair entropy between the LSI and three FLSPs, indicated by $H_{11}, H_{12}$, and $H_{13}$, resp.), three revenue-sharing coefficients (revenue-sharing coefficient between the LSI and three FLSPs, indicated by $\varphi_{1}$, $\varphi_{2}$, and $\varphi_{3}$, resp.), and total fair entropy $(H)$ can be severally drawn; they are shown in Figures 8, 9, and 10.

Figure 8 shows that fair entropies between the LSI and each FLSP are less than 1 but can be infinitely close to 1 in the case of "one to three." The maximum of each entropy is $H_{11}^{*}=H_{12}^{*}=H_{13}^{*}=0.9999$ and shows a declining trend with the increase of the customized level.

Similar to Figure 4, Figure 9 shows that all three revenuesharing coefficients show a trend of first increasing and then decreasing with the increase of $M$. The maximum of three revenue-sharing coefficients can be found: $\varphi_{1}^{*}=0.5872, \varphi_{2}^{*}=$ 0.5990 , and $\varphi_{3}^{*}=0.5922$.

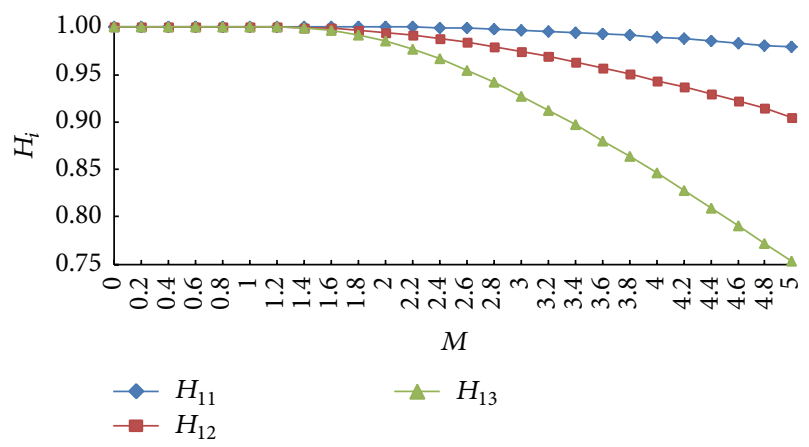

FIGURE 8: Three absolutely fair entropy value curves under different $M$.

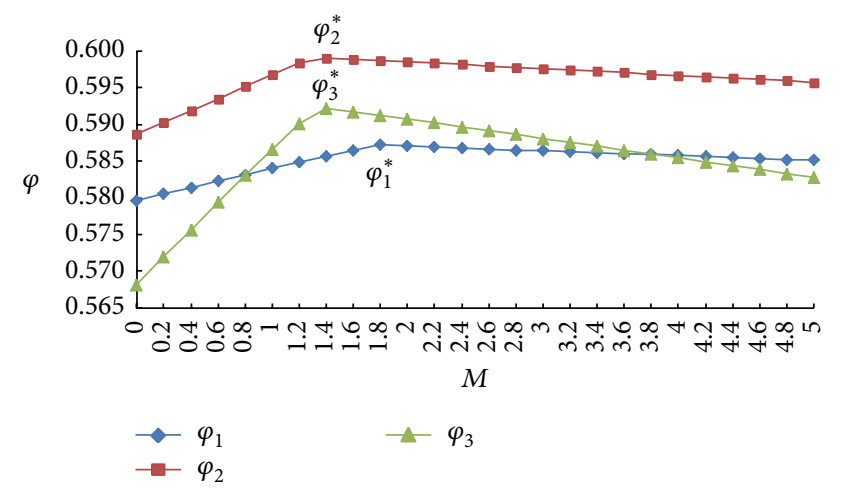

FIGURE 9: Three revenue-sharing coefficient value curves under different $M$.

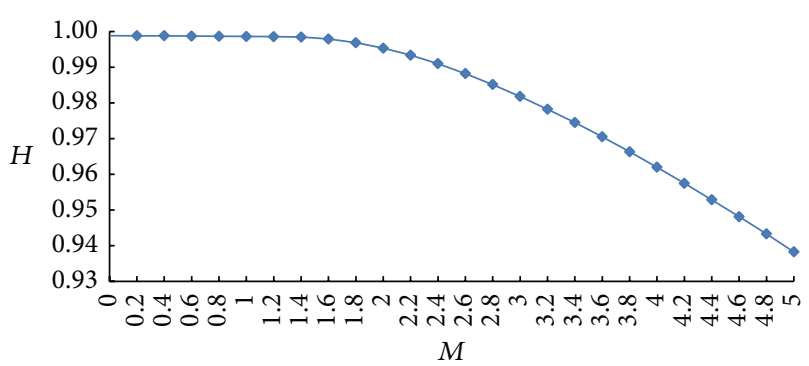

FIGURE 10: Total fair entropy value curve under different $M$.

Figure 10 indicates the trend of total fair entropy changing with $M$, which is decrease $d$ and has its maximum at $H^{*}=$ 0.9988. By observing Figure 10, the total fair entropy can be infinitely close to 1 , and when $M<1.4$, it stays above 0.998 with a tiny drop. These numbers indicate that there exists a better interval of customized level that can make entropy stay at a high level.

Similar to the "one to one" model, in this "one to $N$ " model, the price of final service product is constant, so, in order to discuss the influence of final service price on revenue and fair entropy, we choose $P=14.6$ and $P=15.4$ to compare with the initial price $P=15$, and the changes of the three revenue-sharing coefficients under different prices are shown in Figures 11, 12, and 13; the change of fair entropy under different price is shown in Figure 14. 


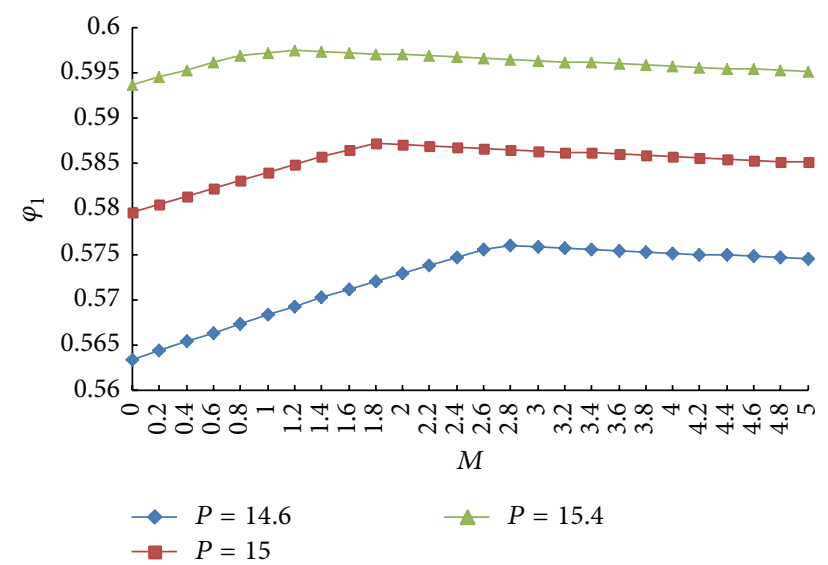

FIGURE 11: Value curves of the revenue-sharing coefficient $\varphi_{1}$ under different prices.

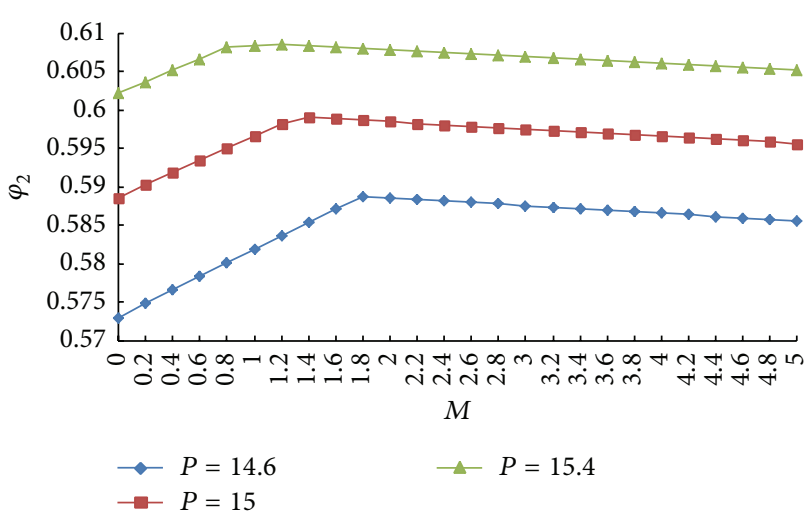

FIGURE 12: Value curves of the revenue-sharing coefficient $\varphi_{2}$ under different prices.

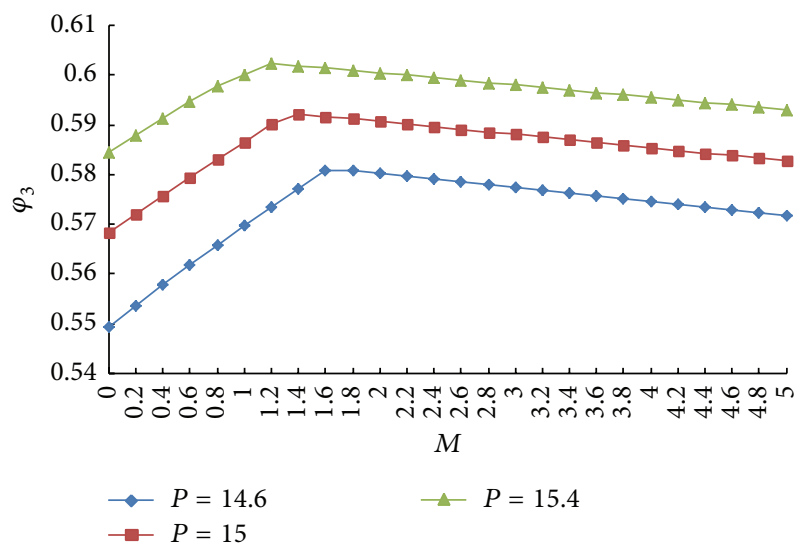

FIGURE 13: Value curves of the revenue-sharing coefficient $\varphi_{3}$ under different prices.

Figures 10, 11, and 12 indicate that, under certain $M$, with the increase of price, the three revenue-sharing coefficients will also increase, which means that the increase of price will benefit the integrator.

Figure 13 shows that, under certain $M$, with the increase of price, the total fair entropy will decrease, which means the

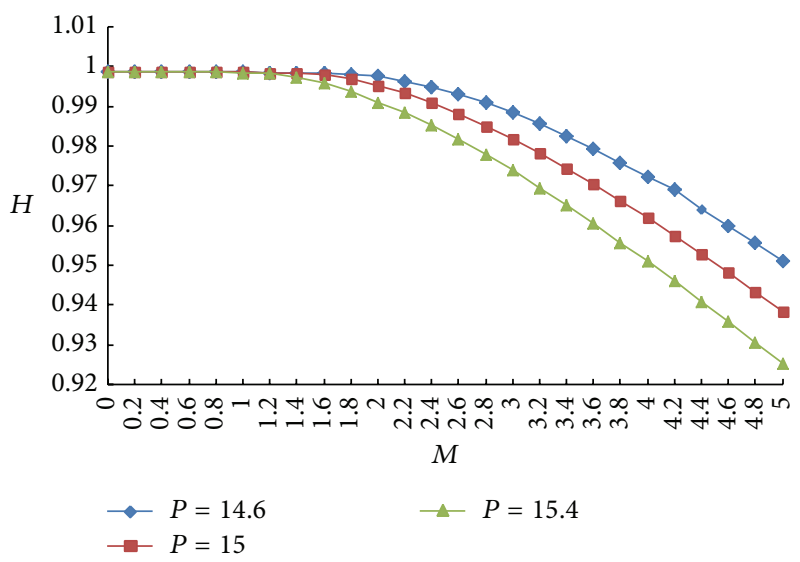

FIgURE 14: Total fair entropy value curve under different prices.

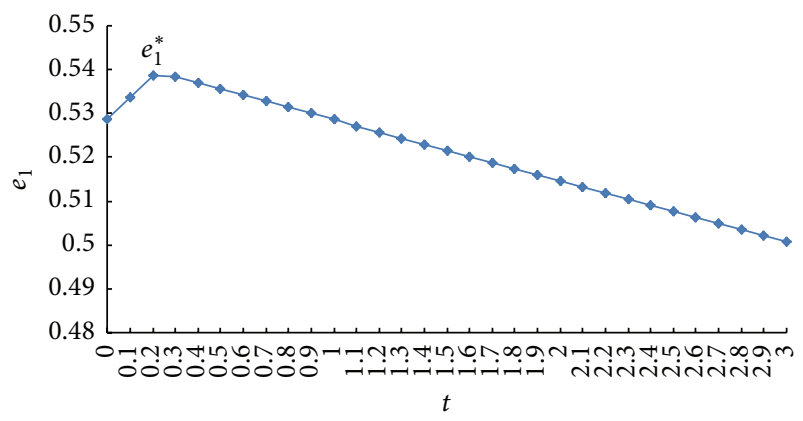

FIGURE 15: $e_{1}$ under a different customized level.

increase of price will lower the fairness of the whole supply chain.

6.3. The Numerical Analysis of the "One to One" Model in Three-Echelon LSSC. The notations and formulas involved in the logistics service supply chain model composed of a single LSI and a single FLSP and a single subcontractor are as follows.

It is assumed that customized level $t$ follows the uniform distribution in interval of $[0,8]$; that is, $t \sim U(0,8.8), D(t)=$ $8.1+1.8 t-0.5 t^{2}, C_{R}=0.5+0.25 t, w_{R}=0.3+1 / 3 * t, w_{S}=$ $0.3+0.25 * t, P=15, C_{u}(P)=3.9, C_{S}=0.4, C_{I}=0.3, l_{1}=3.5$, $l_{2}=3.2, \mu=13, \sigma^{2}=6, H_{0}=0.6, \gamma^{\prime}=0.6$, and $\gamma^{\prime \prime}=0.55$. Most of the data used here are referring to Liu et al. [3]; others are assumed according to the practical business data.

By changing the value of the customized level, the variation trend of the corresponding revenue-sharing coefficient and overall fair entropy can be found.

As shown in Figure 15, with the increase of the customized level, $e_{1}$ first increases and then decreases, which is the same as Figure 4 . But $e_{2}$ keeps increasing with the increase of the customized level, as shown in Figure 16. That is because before $e_{1}^{*}$ the revenue-sharing ratio of $R$ will increase with the increase of the customized level, which means the revenuesharing ratio of $S$ and $I$ will decrease, so FLSP $S$ will improve the revenue-sharing ratio of $S$ between $S$ and $I$ to maximize its own profit; then after $e_{1}^{*}$ the revenue-sharing ratio of $R$ 


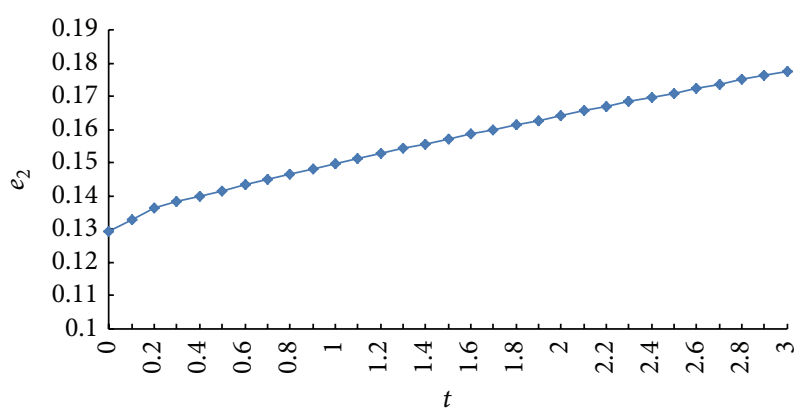

FIgURE 16: $e_{2}$ under a different customized level.

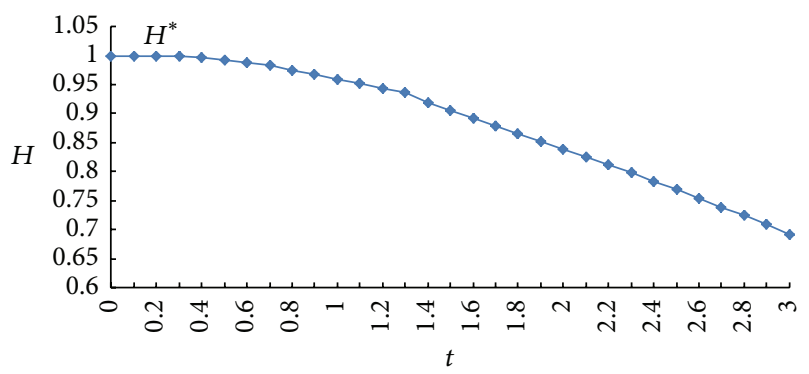

FIgURE 17: $H$ under a different customized level.

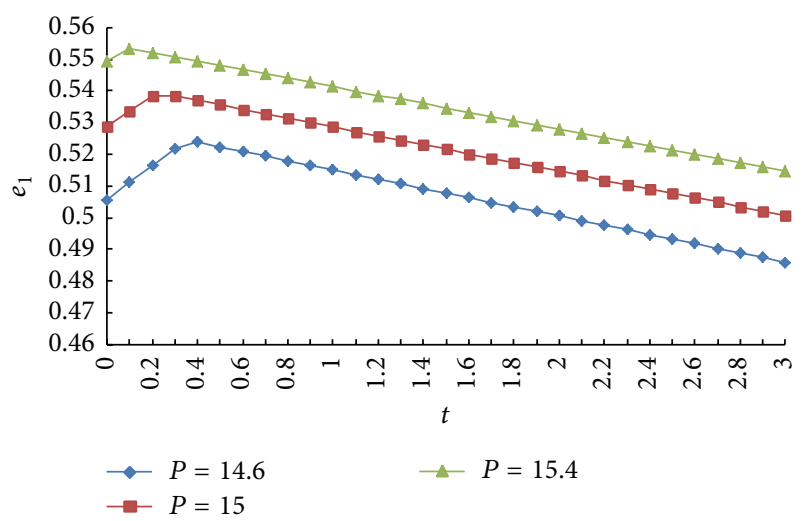

FIGURE 18: Value curves of the revenue-sharing coefficient $e_{1}$ under different prices.

will decrease with the increase of the customized level, which means the revenue-sharing ratio of $S$ and $I$ will increase, but Figure 16 shows that the revenue-sharing ratio of $S$ between $S$ and $I$ is very low; FLSP $S$ will try to share more benefit, so value curve of $e_{2}$ will keep increasing.

Figure 17 is similar to Figure 5, which indicates that, in three-echelon LSSC, the fair entropy also can reach the maximum; that is $H^{*}=1$. With the increase of the customized level, fair entropy decreases gradually with a low speed.

Similar to the "one to one" model in two-echelon LSSC, in this three-echelon model, the price of final service product is constant, so, in sensitivity analysis of service price, we choose $P=14.6$ and $P=15.4$ to compare with the initial price $P=$ 15 , and the changes of the two kinds of revenue-sharing coefficients under different prices are shown in Figures 18 and 19;

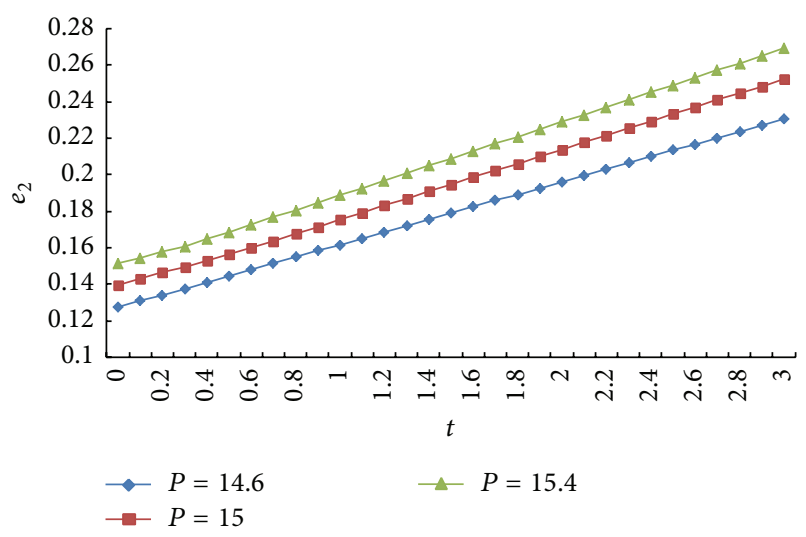

FIGURE 19: Value curves of the revenue-sharing coefficient $e_{2}$ under different prices.

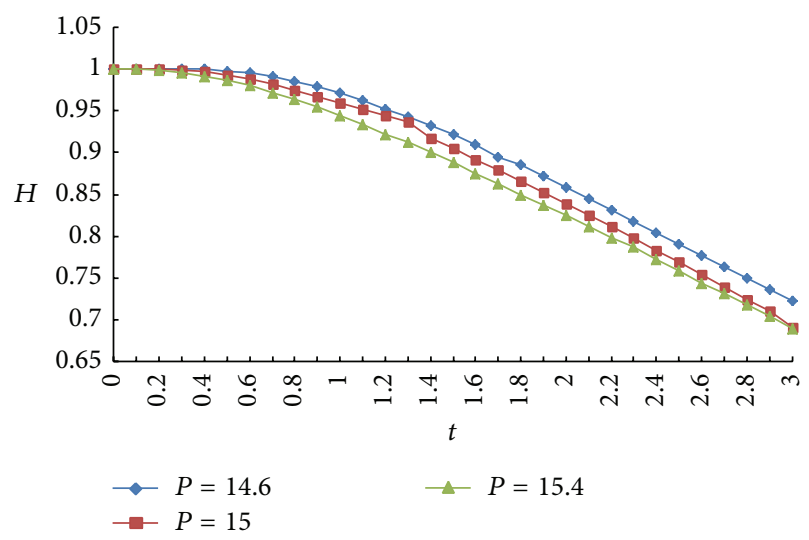

FIGURE 20: Total fair entropy value curve under different prices.

the change of fair entropy under different price is shown in Figure 20.

As shown in Figure 18, which is similar to Figure 6, under the certain customized level, with an increase of the price, the optimal revenue-sharing coefficient of $R$ is increased. Figure 19 indicates that, under the certain customized level, with an increase of the price, the optimal revenue-sharing coefficient of $S$ between $S$ and $I$ also increases.

As shown in Figure 20, with three different prices, all the fair entropies can reach the maximum, which means the LSSC can reach absolutely fairness, similar to Figure 7; with the increase of price, the total fair entropy will decrease.

6.4. Example Result Analysis. By analyzing the example results and Figures 1-20, the conclusions can be drawn as follows.

(1) In the case of a single LSI and single FLSP, fair entropy of the LSI and FLSP in a revenue-sharing contract can reach 1 (that means absolute fair) under a specific interval of customized level (such as $[0,0.15]$ in this example). But, with an increase in the customized level, the fair entropy between the LSI and FLSP shows a trend of descending.

(2) Whether in the case of "one to one" or "one to $N$," the revenue-sharing coefficient of the LSI always shows a trend 
of first increasing and then decreasing with the increase in the customized level; namely, an optimal customized level maximizes the revenue-sharing coefficient.

(3) As shown in Figure 5, with the increase of zooming in (or out) of $t$, namely, $M$, under the case of "one to $N$," fair entropy between three FLSPs and an LSI shows a trend of decrease. It suggests that fair entropy between each FLSP and LSI cannot reach absolute fair under the case of "one to $N$ " due to the relatively fair factors between FLSPs.

(4) In the case of "one to $N$," total fair entropy decreases with the increase of $M$, although it cannot reach the absolute maximum 1; there exists an interval that keeps the total fair entropy at a high level, which is close to 1.

(5) Whether in the case of "one to one" or "one to $N$," when the customized level is certain, the revenue-sharing coefficient of the LSI will increase with the increase of price, but the total fair entropy will decrease.

(6) In the case of "one to one" model in three-echelon LSSC, there are two kinds of revenue-sharing coefficients; the revenue-sharing coefficient of the LSI will first increase and then decrease with the increase of the customized level; when the customized level is certain, the revenue-sharing coefficient of the LSI will increase with the increase of price; the revenue-sharing coefficient of the FLSP between FLSP and subcontractor will keep increasing with the increase of the customized level. When the customized level is certain, the revenue-sharing coefficient of the FLSP will also increase with the increase of price. For the "one to one" model in three-echelon LSSC, the total fair entropy also can reach the maximum, and, with the increase of price, the total fair entropy will decrease.

\section{Conclusions and Management Insights}

7.1. Conclusions. Based on MC service mode, this paper considered the profit fairness factor of supply chain members and constructed a revenue-sharing contract model of logistics service supply chain. Combined with examples to analyze the effect of service customized level on optimal revenuesharing coefficient and fair entropy, this paper also raised an intuitional conclusion and unforeseen result. In particular, the intuitional conclusion has the following several aspects:

(1) Similar to the conclusion of Liu et al. [3], there exists an optimal customized level range that makes the LSI and FLSP get absolutely fair in a revenue-sharing contract between only a single LSI and a single FLSP. But, under the "one to $N$ " condition, there exists an interval of customized level value that maximizes the fair entropy provided by the LSI and N FLSPs but cannot guarantee that the fair entropy is equal to 1 .

(2) Under the situation of "one to one" and "one to N," with the increase of the customized level, the revenuesharing coefficient of the LSI showed a trend of first increasing and then decreasing. This illuminates that there exists an optimal customized level that makes revenue-sharing coefficient reach the maximum.
(3) For "one to one" model in three-echelon LSSC, there exists an interval of customized level value that maximizes the fair entropy which makes the LSI, the FLSP, and the subcontractor get absolutely fair in a revenuesharing contract.

In addition, two unforeseen conclusions are put forward in this paper:

(1) In the case of "one to one", the interval of customized level that can realize absolute fair is limited. Supply chain fair entropy will decrease as the customized level increases when the degree surpasses the maximum of the interval.

(2) In the case of "one to $N$," considering the fairness factor between FLSPs, the revenue distribution between the LSI and each FLSP will not reach absolute fair. But overall fair entropy will approach absolute fairness when the customized level is in a specified range.

(3) Whether in the case of "one to one" or "one to N" in two-echelon LSSC, the increase of price will benefit the integrator but will reduce the fairness of the whole supply chain.

(4) Under the situation of "one to one" model in threeechelon LSSC, the revenue-sharing coefficient of the LSI showed a trend of first increasing and then decreasing, which means there is an optimal customized level that makes the revenue-sharing coefficient of the LSI reach its maximum. The revenuesharing coefficient of the FLSP between FLSP and subcontractor showed a trend of increasing.

(5) Under the situation of "one to one" model in threeechelon LSSC, the increase of price will benefit the integrator but will reduce the fairness of the whole supply chain.

7.2. Management Insights. The research conclusions of this paper have important significance for the LSI. First, whether in "one to one" or "one to $N$ " when operating in reality, the customized level can be restricted in a rational range by consulting with the customer. This will impel the fairness between the LSI and FLSP to the maximum and sustain the revenue-sharing contract relationship. Second, in the case of "one to $N$," profits between the LSI and each FSLP cannot achieve absolute fair; therefore, it is not necessary for the LSI to achieve absolute fair with all FLSPs. Third, the LSI can try to choose the FLSP with greater flexibility when the customized level changes. For example, if the customer needs time to be customized, the LSI can choose the FLSP that has flexibility in time preferentially. Not only will it meet the need of customers but also it is good for obtaining larger supply chain total fair entropy between the LSI and FLSP and for realizing the long-term coordination contract. Fourth, to guarantee the fairness of all the members in LSSC, since the increase of price will obviously benefit the integrator, FLSP and subcontractor can participate into the price setting before the revenue-sharing contract is signed. 
7.3. Research Limitation and Future Research Directions. There are some defects in the revenue-sharing contracts established in this paper. For example, this paper assumed that the final price of the LSI's service products for the customer is a constant value, but, in fact, the higher the customized level is the higher the market price may be. Future research can assume that the final price of service is related to the level of customization.

Otherwise, in order to simplify the model, this paper only considered two stages of logistics service supply chain, but there have always been three in reality. Future research can try to extend the numbers of stages to three for enhancing the utility of the model.

\section{Appendices}

\section{A. The Calculation Details of Stackelberg Game in "One to $N$ " Model}

This appendix contains the calculation details of $w_{i}$ and $Q_{i}$ in the "one to $N$ " model.

For the Stackelberg game, the revenue expectation functions of $R$ and $S_{i}$ are as follows:

$$
\begin{aligned}
E\left(\pi_{R i}\right)= & P_{i}\left(Q_{i}-b_{i}\right)-w_{i} Q_{i}-C_{R} Q_{i} \\
& -C_{u}\left(P_{i}\right)\left(\mu_{i}-Q_{i}+b_{i}\right)-\frac{w_{i}^{2}}{k_{i} \sigma_{i}^{2}} b_{i} \\
E\left(\pi_{S i}\right)= & {\left[w_{i}-C_{S i}\right] Q_{i}+\frac{w_{i}^{2}}{l_{i} \sigma_{i}^{2}} b_{i} . }
\end{aligned}
$$

Among them, $b_{i}=\int_{0}^{Q_{i}}\left[Q_{i}-D_{0 i}-k t_{i}+(1 / 2) h t_{i}{ }^{2}\right] f\left(t_{i}\right) d t$, and $s_{i}=\partial b_{i} / \partial Q_{i}$.

So $s_{i}=F\left(Q_{i}\right)+\left[(1 / 2) h Q_{i}{ }^{2}+(1-k) Q_{i}-D_{0 i}\right] f\left(Q_{i}\right)$, and $\partial S\left(Q_{i}\right) / \partial Q_{i}=1-s_{i}$.

First, to maximize the profits, the following first-order condition should be satisfied:

$$
\frac{\partial E\left(\pi_{S i}\right)}{\partial w_{i}}=Q_{i}+\frac{2 w_{i}}{l_{i} \sigma_{i}^{2}} b_{i}=0 .
$$

Obtaining the result, $w_{i}=-Q_{i} l_{i} \sigma_{i}^{2} / 2 b_{i}$.

To maximize the profits of each members of supply chain, the following first-order condition should be satisfied:

$$
\begin{aligned}
\frac{\partial E\left(\pi_{R i}\right)}{\partial Q_{i}}= & {\left[P_{i}+C_{u}\left(P_{i}\right)\right]\left(1-s_{i}\right)-C_{R i}-w_{i} } \\
& -\frac{s_{i} w_{i}^{2}}{l_{i} \sigma_{i}^{2}}=0
\end{aligned}
$$

Then the second derivative is less than 0 ; namely, $\partial^{2} E\left(\pi_{R i}\right) / \partial Q_{i}^{2}<0$.

From formula (A.3), under the Stackelberg game, we can obtain the optimal purchase volumes of capacity $Q_{i}^{\prime \prime}$ and $w_{i}^{\prime \prime}$, and the optimal profits expectation of $R$ is $E\left(\pi_{R i}^{\prime \prime}\right)$ and that of $S_{i}$ is $E\left(\pi_{S i}^{\prime \prime}\right)$.
Then the optimal logistics capacity volumes that the LSI purchases from all FLSPs can be calculated: $Q^{\prime \prime}=\sum_{i=1}^{N} Q_{i}^{\prime \prime}$. And the optimal expected total profits of $R$ are $E\left(\pi_{R}^{\prime \prime}\right)=$ $\sum_{i=1}^{N} E\left(\pi_{R i}^{\prime \prime}\right)$. The expectation total profits of all FLSPs are $E\left(\pi_{S}^{\prime \prime}\right)=\sum_{i=1}^{N} E\left(\pi_{S i}^{\prime \prime}\right)$.

\section{B. The Calculation Details of the Fair Entropy between the LSI and the FLSP $i$ in "One to $N$ " Model}

This appendix contains the calculation details of the fair entropy between the LSI and FLSP $i$. Consider

$$
\begin{aligned}
\xi_{R i} & =\frac{\Delta \theta_{R i}}{\varphi_{i} \gamma_{i} T_{R i}}, \\
\xi_{S i} & =\frac{\Delta \theta_{S i}}{\left(1-\varphi_{i}\right)\left(1-\gamma_{i}\right) T_{S i}} .
\end{aligned}
$$

Among them, $T_{R i}$ and $T_{S i}$, respectively, indicate the total cost of the LSI and that of FLSP in supply chain branch.

Introducing the entropy makes the following standardized transformation:

$$
\begin{aligned}
& \xi_{R i}^{\prime}=\frac{\left(\xi_{R i}-\bar{\xi}_{i}\right)}{\sigma_{i}}, \\
& \xi_{S i}^{\prime}=\frac{\left(\xi_{S i}-\bar{\xi}_{i}\right)}{\sigma_{i}} .
\end{aligned}
$$

$\bar{\xi}_{i}$ is average value and $\sigma_{i}$ is standardized deviation.

To eliminate the negative value, make a coordinate translation [44]: $\xi_{R i}^{\prime \prime}=K_{1}+\xi_{R i}^{\prime} ; \xi_{S i}^{\prime \prime}=K_{1}+\xi_{S i}^{\prime}, K_{1}$ is the range of coordinate translation and processes the normalization: $\lambda_{R i}=\xi_{R i}^{\prime \prime} /\left(\xi_{R i}^{\prime \prime}+\xi_{S i}^{\prime \prime}\right)$ and $\lambda_{S i}=\xi_{S i}^{\prime \prime} /\left(\xi_{R i}^{\prime \prime}+\xi_{S i}^{\prime \prime}\right)$.

Obtain $\lambda_{R i}$ and $\lambda_{S i}$ and substitute them into the function to calculate the fair entropy of the whole supply chain: $H_{1 i}=$ $-(1 / \ln m) \sum_{i=1}^{m} \lambda_{i} \ln \lambda_{i}$. For $0 \leq H_{1 i} \leq 1$, the fair entropy between the LSI and FLSP $i$ in this model is

$$
H_{1 i}=-\frac{1}{\ln 2}\left(\lambda_{R i} \ln \lambda_{R i}+\lambda_{S i} \ln \lambda_{S i}\right) \text {. }
$$

\section{The Calculation Details of Stackelberg Game in "One to One" Model of Three- Echelon Logistics Service Supply Chains}

First, to maximize the profits of subcontractor $I$, the firstorder condition should be satisfied:

$$
\frac{\partial E\left(\pi_{I}^{\prime \prime}\right)}{\partial w_{2}}=Q+\frac{2 w_{2}}{l_{2} \sigma^{2}} b=0 .
$$

Then $w_{S}=-Q l_{2} \sigma^{2} / 2 b$.

Next, to maximize the profits of FLSP $S$, the first-order condition should be satisfied:

$$
\frac{\partial E\left(\pi_{S}^{\prime \prime}\right)}{\partial w_{R}}=Q+\frac{2 w_{R}}{l_{1} \sigma^{2}} b=0 .
$$

Then $w_{R}=-Q l_{1} \sigma^{2} / 2 b$. 
Finally, to maximize the profits of the LSI, the first-order condition should be satisfied:

$$
\begin{aligned}
\frac{\partial E\left(\pi_{R}^{\prime \prime}\right)}{\partial Q} & =\left[P+C_{u}(P)\right](1-s)-C_{R}-w_{R}-\frac{s w_{R}^{2}}{l_{1} \sigma^{2}} \\
& =0
\end{aligned}
$$

while satisfying the fact that second derivative is less than 0 ; that is, $\partial^{2} E\left(\pi_{R}^{\prime \prime}\right) / \partial Q^{2}<0$.

We can obtain the optimal value of purchasing the capacity $Q^{\prime \prime}$ under the Stackelberg game. And by substituting $Q^{\prime \prime}$ into the expression of $w_{R}$ and $w_{S}$, the corresponding $w_{R}^{\prime \prime}$ and $w_{S}^{\prime \prime}$ can be calculated.

\section{The Calculation Details of the Fair Entropy between $R, S$, and $I$ in "One to One” Model of Three-Echelon Logistics Service Supply Chains}

Since the revenue-sharing coefficients are $e_{1}$ and $e_{2}$, the respective profit growth of the LSI, the FLSP, and subcontractor is

$$
\begin{aligned}
& \Delta \theta_{R}= \frac{E\left(\pi_{R}^{\prime}\right)-E\left(\pi_{R}^{\prime \prime}\right)}{E\left(\pi_{R}^{\prime \prime}\right)}, \\
& \Delta \theta_{S}=\frac{E\left(\pi_{S}^{\prime}\right)-E\left(\pi_{S}^{\prime \prime}\right)}{E\left(\pi_{S}^{\prime \prime}\right)}, \\
& \Delta \theta_{I}=\frac{E\left(\pi_{I}^{\prime}\right)-E\left(\pi_{I}^{\prime \prime}\right)}{E\left(\pi_{I}^{\prime \prime}\right)} .
\end{aligned}
$$

Considering the different weights of the LSI and FLSP and the FLSP and subcontractor in the supply chain, suppose the weights of each are given. It is assumed that the weight of the LSI is $\gamma_{1}$ in the relationship of LSP and FLSP; thus the weight of FLSP is $1-\gamma_{1}$ in the relationship of LSP and FLSP; the weight of the FLSP is $\gamma_{2}$ in the relationship of FLSP and subcontractor; thus the weight of the subcontractor is $1-\gamma_{2}$ in the relationship of FLSP and subcontractor; then the profit growth on unit-weight resource of the LSI, the FLSP, and subcontractor is

$$
\begin{aligned}
& \xi_{1}=\frac{\Delta \theta_{R}}{e_{1} \gamma_{1} T_{R}}, \\
& \xi_{2}=\frac{\Delta \theta_{S}}{\left(1-e_{1}\right)\left(1-\gamma_{1}\right) e_{2} \gamma_{2} T_{S}}, \\
& \xi_{3}=\frac{\Delta \theta_{I}}{\left(1-e_{1}\right)\left(1-\gamma_{1}\right)\left(1-e_{2}\right)\left(1-\gamma_{2}\right) T_{I}} .
\end{aligned}
$$

The total cost of the LSI is

$$
\begin{aligned}
T_{R}= & w_{R} Q+C_{R} Q+e_{1} C_{u}(P)[\mu-S(Q)] \\
& +V_{1}[Q-S(Q)] .
\end{aligned}
$$

The total cost of the FLSP is

$$
\begin{aligned}
T_{S}= & C_{S} Q+w_{S} Q+e_{2}\left(1-\varphi_{1}\right) C_{u}(P)[\mu-S(Q)] \\
& +V_{2}[Q-S(Q)] .
\end{aligned}
$$

The total cost of the subcontractor is

$$
T_{I}=C_{I} Q+\left(1-e_{2}\right)\left(1-e_{1}\right) C_{u}(P)[\mu-S(Q)] .
$$

Then we introduce the concept of entropy:

$$
\begin{aligned}
& \xi_{1}^{\prime}=\frac{\left(\xi_{1}-\bar{\xi}\right)}{\sigma}, \\
& \xi_{2}^{\prime}=\frac{\left(\xi_{2}-\bar{\xi}\right)}{\sigma}, \\
& \xi_{3}^{\prime}=\frac{\left(\xi_{3}-\bar{\xi}\right)}{\sigma} .
\end{aligned}
$$

Among them,

$$
\begin{aligned}
\bar{\xi} & =\frac{1}{3} \sum_{i=1}^{3} \xi_{i}, \\
\sigma & =\sqrt{\frac{1}{3} \sum_{i=1}^{3}\left(\xi_{i}-\bar{\xi}\right)^{2}} .
\end{aligned}
$$
$\varepsilon_{i}^{\prime}$.

They are the average value and the standard deviation of

Similar to the "one to one" model in two-echelon LSSC, then, calculating the ratio $\lambda_{i}$ of $\xi_{i}^{\prime \prime}$, set

$$
\begin{aligned}
& \lambda_{1}=\frac{\xi_{1}^{\prime \prime}}{\xi_{1}^{\prime \prime}+\xi_{2}^{\prime \prime}+\xi_{3}^{\prime \prime}}, \\
& \lambda_{2}=\frac{\xi_{2}^{\prime \prime}}{\xi_{1}^{\prime \prime}+\xi_{2}^{\prime \prime}+\xi_{3}^{\prime \prime}}, \\
& \lambda_{3}=\frac{\xi_{3}^{\prime \prime}}{\xi_{1}^{\prime \prime}+\xi_{2}^{\prime \prime}+\xi_{3}^{\prime \prime}} .
\end{aligned}
$$

After obtaining $\lambda_{1}, \lambda_{2}$, and $\lambda_{3}$, the fair entropy of whole supply chain is

$$
H=-\frac{1}{\ln 3}\left(\lambda_{1} \ln \lambda_{1}+\lambda_{2} \ln \lambda_{2}+\lambda_{3} \ln \lambda_{3}\right) .
$$

\section{Conflict of Interests}

The authors declare that there is no conflict of interests regarding the publication of this paper.

\section{Acknowledgment}

This research is supported by the National Natural Science Foundation of China (Grant no. 71372156) and supported by Humanity and Social Science Youth foundation of Ministry of Education of China (Grant no. 13YJC630098) and sponsored by China State Scholarship Fund and Independent Innovation Foundation of Tianjin University. The reviewers' comments are also highly appreciated. 


\section{References}

[1] D. James D Jr. and K. E. Spier, "Revenue sharing and vertical control in the video rental industry," The Journal of Industrial Economics, vol. 49, no. 3, pp. 223-245, 2001.

[2] S. Li, Z. Zhu, and L. Huang, "Supply chain coordination and decision making under consignment contract with revenue sharing," International Journal of Production Economics, vol. 120, no. 1, pp. 88-99, 2009.

[3] W.-H. Liu, X.-C. Xu, and A. Kouhpaenejad, "Deterministic approach to the fairest revenue-sharing coefficient in logistics service supply chain under the stochastic demand condition," Computers \& Industrial Engineering, vol. 66, no. 1, pp. 41-52, 2013.

[4] K. L. Choy, C.-L. Li, S. C. K. So, H. Lau, S. K. Kwok, and D. W. K. Leung, "Managing uncertainty in logistics service supply chain," International Journal of Risk Assessment \& Management, vol. 7, no. 1, pp. 19-43, 2007.

[5] W. H. Liu, X. C. Xu, Z. X. Ren, and Y. Peng, "An emergency order allocation model based on multi-provider in two-echelon logistics service supply chain," Supply Chain Management, vol. 16, no. 6, pp. 391-400, 2011.

[6] H. F. Martin, "Mass customization at personal lines insurance center," Planning Review, vol. 21, no. 4, pp. 27-56, 1993.

[7] W. H. Liu, W. Qian, D. L. Zhu, and Y. Liu, "A determination method of optimal customization degree of logistics service supply chain with mass customization service," Discrete Dynamics in Nature and Society, vol. 2014, Article ID 212574, 14 pages, 2014.

[8] J. Liou and L. Yen, "Using decision rules to achieve MC of airline services," European Journal of Operational Research, vol. 205, no. 3, pp. 690-686, 2010.

[9] S. S. Chauhan and J.-M. Proth, "Analysis of a supply chain partnership with revenue sharing," International Journal of Production Economics, vol. 97, no. 1, pp. 44-51, 2005.

[10] H. Krishnan and R. A. Winter, "On the role of revenue-sharing contracts in supply chains," Operations Research Letters, vol. 39, no. 1, pp. 28-31, 2011.

[11] Q. Pang, "Revenue-sharing contract of supply chain with wasteaverse and stockout-averse preferences," in Proceedings of the IEEE International Conference on Service Operations and Logistics, and Informatics (IEEE/SOLI '08), pp. 2147-2150, October 2008.

[12] B. J. Pine II and D. Stan, MC: The New Frontier in Business Competition, Harvard Business School Press, Boston, Mass, USA, 1993.

[13] F. Salvador, P. M. Holan, and F. Piller, "Cracking the code of MC," MIT Sloan Management Review, vol. 50, no. 3, pp. 71-78, 2009.

[14] Y. X. Feng, B. Zheng, J. R. Tan, and Z. Wei, "An exploratory study of the general requirement representation model for product configuration in mass customization mode," The International Journal of Advanced Manufacturing Technology, vol. 40, no. 7, pp. 785-796, 2009.

[15] D. Yang, M. Dong, and X.-K. Chang, "A dynamic constraint satisfaction approach for configuring structural products under mass customization," Engineering Applications of Artificial Intelligence, vol. 25, no. 8, pp. 1723-1737, 2012.

[16] C. Welborn, "Customization index: evaluating the flexibility of operations in a MC environment," The ICFAI University Journal of Operations Management, vol. 8, no. 2, pp. 6-15, 2009.
[17] X.-F. Shao, "Integrated product and channel decision in mass customization," IEEE Transactions on Engineering Management, vol. 60, no. 1, pp. 30-45, 2013.

[18] H. Wang, "Defects tracking in mass customisation production using defects tracking matrix combined with principal component analysis," International Journal of Production Research, vol. 51, no. 6, pp. 1852-1868, 2013.

[19] D.-C. Li, F. M. Chang, and S.-C. Chang, "The relationship between affecting factors and mass-customisation level: the case of a pigment company in Taiwan," International Journal of Production Research, vol. 48, no. 18, pp. 5385-5395, 2010.

[20] F. S. Fogliatto, G. J. C. Da Silveira, and D. Borenstein, "The mass customization decade: an updated review of the literature," International Journal of Production Economics, vol. 138, no. 1, pp. $14-25,2012$.

[21] A. Bardakci and J. Whitelock, "Mass-customisation in marketing: the consumer perspective," Journal of Consumer Marketing, vol. 20, no. 5, pp. 463-479, 2003.

[22] H. Cavusoglu, H. Cavusoglu, and S. Raghunathan, "Selecting a customization strategy under competition: mass customization, targeted mass customization, and product proliferation," IEEE Transactions on Engineering Management, vol. 54, no. 1, pp. 12 28, 2007.

[23] L. Liang and J. Zhou, "The optimization of customized level based on MC," Chinese Journal of Management Science, vol. 10, no. 6, pp. 59-65, 2002 (Chinese).

[24] L. Zhou, H. J. Lian, and J. H. Ji, "An analysis of customized level on MC," Chinese Journal of Systems \& Management, vol. 16, no. 6, pp. 685-689, 2007 (Chinese).

[25] P. Goran and V. Helge, "Growth strategies for logistics service providers: a case study," The International Journal of Logistics Management, vol. 12, no. 1, pp. 53-64, 2001.

[26] J. Korpela, K. Kyläheiko, A. Lehmusvaara, and M. Tuominen, "An analytic approach to production capacity allocation and supply chain design," International Journal of Production Economics, vol. 78, no. 2, pp. 187-195, 2002.

[27] A. Henk and V. Bart, "Amplification in service supply chain: an exploratory case study," Production \& Operations Management, vol. 12, no. 2, pp. 204-223, 2003.

[28] A. Martikainen, P. Niemi, and P. Pekkanen, "Developing a service offering for a logistical service provider-case of local food supply chain," International Journal of Production Economics, vol. 157, no. 1, pp. 318-326, 2014.

[29] R. L. Rhonda, K. D. Leslie, and J. V. Robert, "Supply chain flexibility: building ganew model," Global Journal of Flexible Systems Management, vol. 4, no. 4, pp. 1-14, 2003.

[30] W. Liu, Y. Yang, X. Li, H. Xu, and D. Xie, "A time scheduling model of logistics service supply chain with mass customized logistics service," Discrete Dynamics in Nature and Society, vol. 2012, Article ID 482978, 18 pages, 2012.

[31] W. H. Liu, Y. Mo, Y. Yang, and Z. Ye, "Decision model of customer order decoupling point on multiple customer demands in logistics service supply chain," Production Planning \& Control, vol. 26, no. 3, pp. 178-202, 2015.

[32] I. Giannoccaro and P. Pontrandolfo, "Negotiation of the revenue sharing contract: an agent-based systems approach," International Journal of Production Economics, vol. 122, no. 2, pp. 558566, 2009.

[33] A. Z. Zeng, J. Hou, and L. D. Zhao, "Coordination through revenue sharing and bargaining in a two-stage supply chain," in Proceedings of the IEEE International Conference on Service 
Operations and Logistics, and Informatics (SOLI '07), pp. 38-43, IEEE, Philadelphia, Pa, USA, August 2007.

[34] Z. Qin, "Towards integration: a revenue-sharing contract in a supply chain," IMA Journal of Management Mathematics, vol. 19, no. 1, pp. 3-15, 2008.

[35] J. Hou, A. Z. Zeng, and L. Zhao, "Achieving better coordination through revenue-sharing and bargaining in a two-stage supply chain," Computers and Industrial Engineering, vol. 57, no. 1, pp. 383-394, 2009.

[36] F. El Ouardighi, "Supply quality management with optimal wholesale price and revenue sharing contracts: a two-stage game approach," International Journal of Production Economics, vol. 156, pp. 260-268, 2014.

[37] S. Xiang, W. You, and C. Yang, "Study of revenue-sharing contracts based on effort cost sharing in supply chain," in Proceedings of the 5th International Conference on Innovation and Management, vol. I-II, pp. 1341-1345, 2008.

[38] B. van der Rhee, G. Schmidt, J. A. A. van der Veen, and V. Venugopal, "Revenue-sharing contracts across an extended supply chain," Business Horizons, vol. 57, no. 4, pp. 473-482, 2014.

[39] I. Giannoccaro and P. Pontrandolfo, "Supply chain coordination by revenue sharing contracts," International Journal of Production Economics, vol. 89, no. 2, pp. 131-139, 2004.

[40] S. W. Kang and H. S. Yang, "The effect of unobservable efforts on contractual efficiency: wholesale contract vs. revenue-sharing contract," Management Science and Financial Engineering, vol. 19, no. 2, pp. 1-11, 2013.

[41] G. P. Cachon and M. A. Lariviere, "Supply chain coordination with revenue-sharing contracts: strengths and limitations," Management Science, vol. 51, no. 1, pp. 30-44, 2005.

[42] J.-C. Hennet and S. Mahjoub, "Toward the fair sharing of profit in a supply network formation," International Journal of Production Economics, vol. 127, no. 1, pp. 112-120, 2010.

[43] Z.-H. Zou, Y. Yun, and J.-N. Sun, "Entropy method for determination of weight of evaluating indicators in fuzzy synthetic evaluation for water quality assessment," Journal of Environmental Sciences, vol. 18, no. 5, pp. 1020-1023, 2006.

[44] X. Q. Zhang, C. B. Wang, E. K. Li, and C. D. Xu, "Assessment model of ecoenvironmental vulnerability based on improved entropy weight method," The Scientific World Journal, vol. 2014, Article ID 797814, 7 pages, 2014.

[45] C. Erbao, W. Can, and M. Y. Lai, "Coordination of a supply chain with one manufacturer and multiple competing retailers under simultaneous demand and cost disruptions," International Journal of Production Economics, vol. 141, no. 1, pp. 425-433, 2013. 


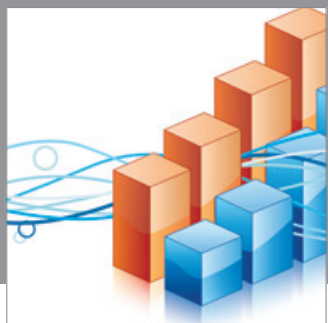

Advances in

Operations Research

mansans

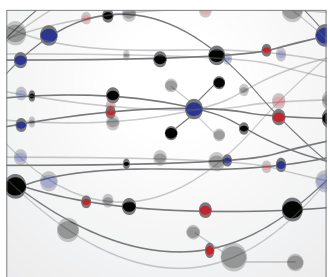

The Scientific World Journal
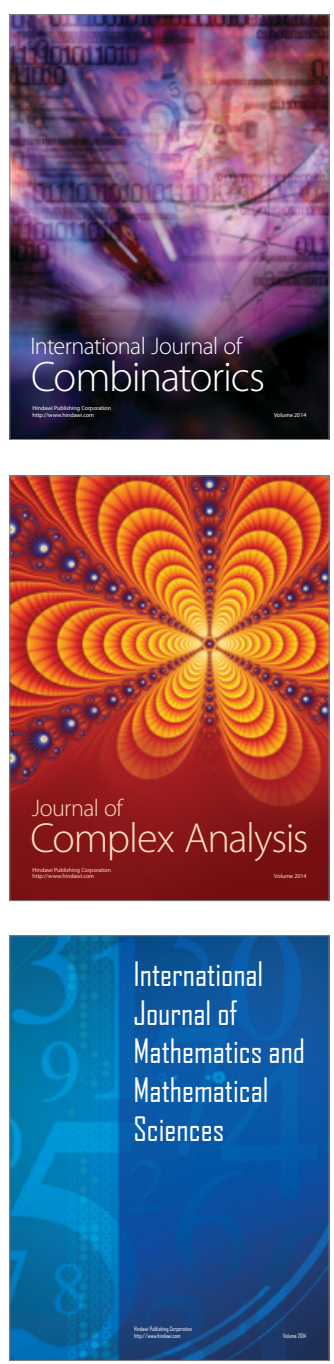
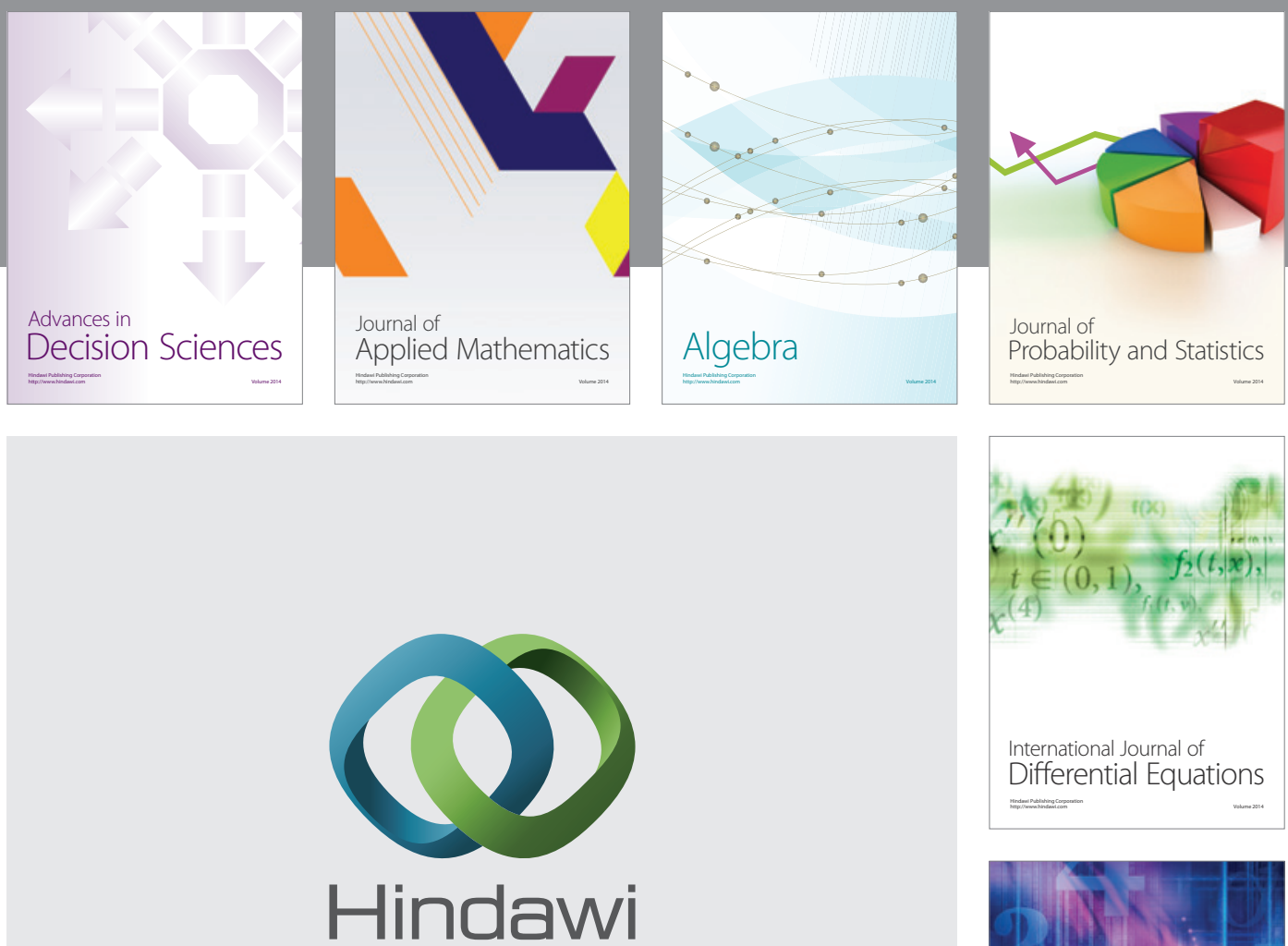

Submit your manuscripts at http://www.hindawi.com
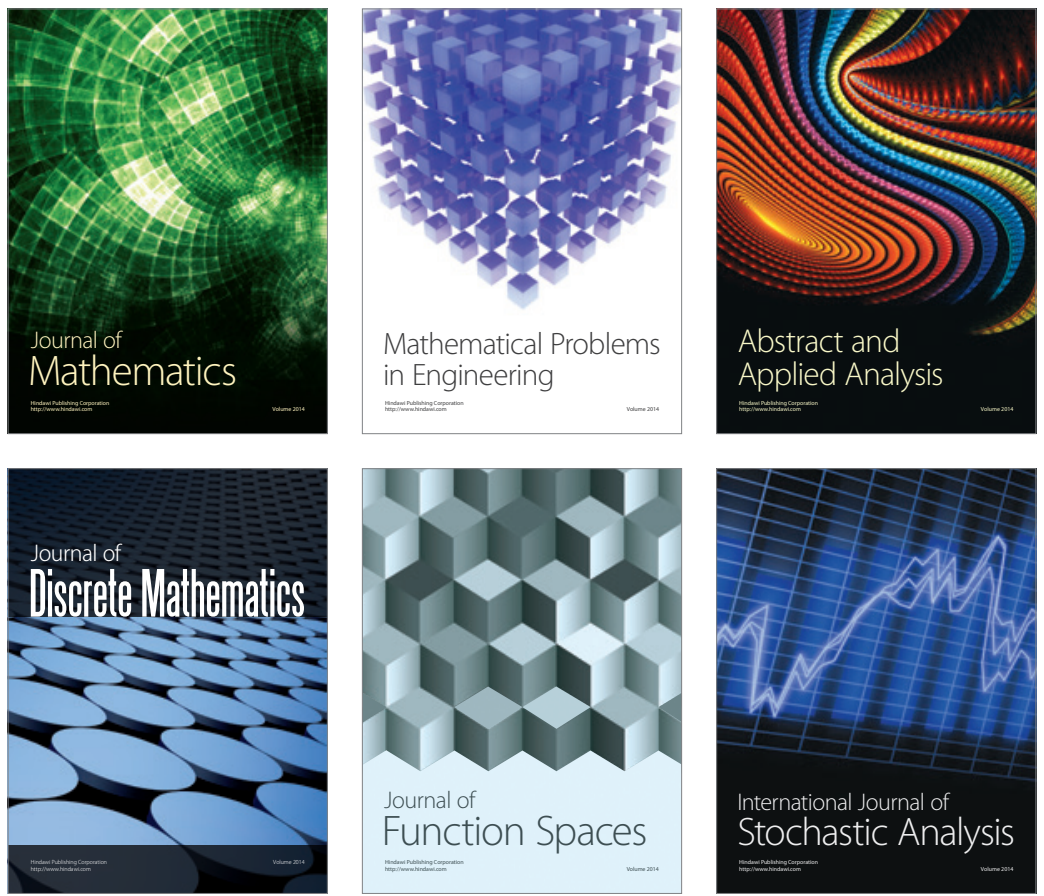

Journal of

Function Spaces

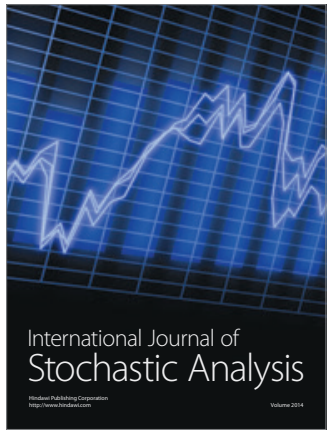

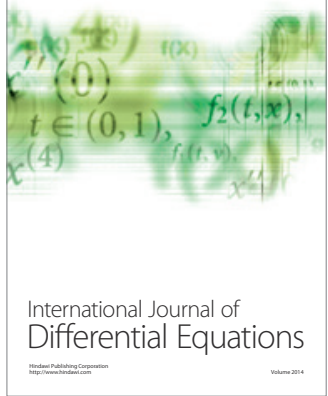
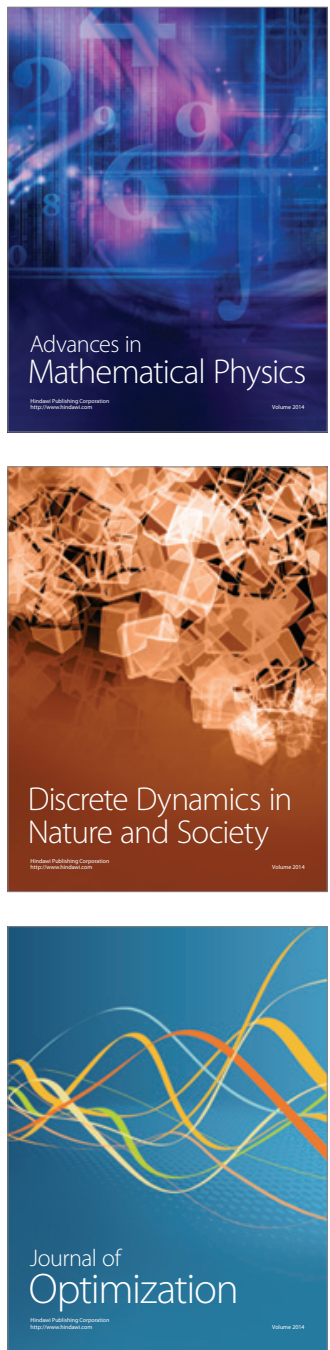